\title{
CAMELE: Collocation-Analyzed Multi-source Ensembled Land
}

\section{Evapotranspiration Data}

$5 \quad{ }^{1}$ State Key Laboratory of Hydroscience and Engineering, Department of Hydraulic

6 Engineering, Tsinghua University. Beijing 100084, China

$7{ }^{2}$ Center for Agricultural Water Research in China, China Agricultural University,

8 Beijing 100083, China

9

10

11 *Correspondence: Hanbo Yang (yanghanbo@tsinghua.edu.cn )

12 


\section{Abstract}

14 Land evapotranspiration (ET) is a key element of Earth's water-carbon system.

15 Accurate estimation of global land ET is essential for better understanding of land16 atmosphere interaction. Past decades have witnessed the generation of various ET 17 products. However, the widely used products still contain inherent uncertainty 18 induced by forcing inputs and imperfect model parameterizations. In addition, direct

19 evaluation of ET products is not feasible due to the lack of sufficient global in-situ 20 observations, which hinders our usage and assimilation. Hence, merging a global 21 dataset as reliable benchmark and exploring evaluation method for ET products are of 22 great importance. The aims of our study were as followed: (1) to design and validate a 23 collocation-based method for ET merging; (2) to generate a long-term (1981-2020) 24 ET product employing ERA5, FLUXCOM, PMLV2, GLDAS and GLEAM at $0.1^{\circ}$ 25 8Daily and $0.25^{\circ}$-Daily resolutions. The produced Collocation-Analyzed Multi-source 26 Ensembled Land Evapotranspiration Data (CAMELE) was then compared with others 27 at point and regional scales. At the point scale, the results showed that the CAMELE 28 performed well over different vegetation coverage. The accuracy of CAMELE was 29 validated against in-situ observations with Pearson Correlation of 0.68, 0.62 and root 30 mean square error of 0.84 and $1.03 \mathrm{~mm} / \mathrm{d}$ on average over $0.1^{\circ}$ and $0.25^{\circ}$, respectively. 31 In terms of Kling-Gupta Efficiency, CAMELE ET obtained results superior (mean 320.52 ) to the second best ERA5 (mean 0.44 ) at $0.1^{\circ}$ basis. For global comparison, the 33 spatial distribution of multi-year average and annual variation were in consistent with 34 others. Our merged product revealed increased ET in South Asia, Northwest Australia, 35 and decreases in Amazon Plain and Congo Basin. The CAMELE products is freely 36 available at https://doi.org/10.5281/zenodo.6283239 (Li et al., 2021). 


\section{Introduction}

40 Land Evapotranspiration, including transpiration, soil evaporation, and evaporation

41 from canopy interception, is the key component of global terrestrial water and energy

42 cycle (Jung et al., 2010; Lian et al., 2018), which accounts for about $60 \%$ of water

43 cycle. As the intermediate variable of soil moisture affecting air temperature, accurate

44 estimation of global land evapotranspiration is critical for understanding the

45 hydrological cycle and land-atmosphere interaction (Miralles et al., 2019; Gentine et

46 al., 2019). Thus, providing a reliable ET dataset as benchmark for further studies is of

47 great importance.

48 During past decades, a great number of studies have investigated and developed

49 different methods for the estimation of global land evapotranspiration, which leads to

50 lots of datasets. Due to the difference in employed algorithms and principles,

51 discrepancies are quite common among different simulations (Restrepo-Coupe et al.,

52 2021; Han and Tian, 2020; Zhang et al., 2021b). In addition, evaluation of ET

53 products is always challenging due to the lack of sufficient observations at global

54 scale, which limits the direct uses of these data (Pan et al., 2020; Baker et al., 2021).

55 Products are often merged to mitigate their uncertainties. Recent studies have

56 explored several approaches to integrate multiple ET products, including Simple

57 Average (SA) (Ershadi et al., 2014), Bayesian Model Average (BMA) (Ma et al.,

58 2020; Zhu et al., 2016), Reliability Ensemble Average method (REA) (Yoo et al.,

59 2020), Empirical Orthogonal Functions (EOF) (Feng et al., 2016) and machine-

60 learning based methods (Chen et al., 2020; Yin et al., 2021). The SA method assigns

61 the same weight to each product, which is practically unreasonable; The BMA

62 method requires a certain input of observations with high quality and relative dense

63 distribution ( $\mathrm{Li}$ et al., 2021); The EOF method requires high computational cost and

64 may introduce uncertainty by unclear refactoring scheme (Le et al., 2017). Behind

65 these methods, the main challenge is to calculate reliable weights for inputs based on

66 a chosen "truth" (Gruber et al., 2020; Koster et al., 2021), either by averaging or 
67 introducing other relative geographical information as benchmark (Zhang et al., 68 2021a). In addition, previous research mostly focused on the estimation of ET at 69 regional scale. For a global simulation, a more simple and reliable method is required.

70 Without the requirement of given reference, collocation analysis methods are widely 71 used to estimate error variances and data-truth correlations by comparing across 72 several independent data sources (Stoffelen, 1998; Gruber et al., 2020) . Lately, these 73 methods have been widely applied in evaluation of various geographical variables 74 estimates, including soil moisture (Chen et al., 2018; Dong et al., 2020c), precipitation 75 (Li et al., 2018; Dong et al., 2020a), ocean wind speed (Ribal and Young, 2020), leaf area index (Jiang et al., 2017), total water storage (Baik et al., 2021), sea ice thickness and surface salinity (Hoareau et al., 2018), and near-surface air temperature (Sun et al., 2021). The original triple-collocation framework has been expanded in recent years. (Su et al., 2014) proposed an instrumental-variable based approach by using a temporally lag-1 time series of one product as the other independent product, which only requires double collocation and is referred as single instrumental variable algorithm, or IVS. Based on that, (Dong et al., 2019) achieved a more robust solution, denoted as double instrumental variable algorithm, or IVD. (Gruber et al., 2016) extends the original algorithm to include a fourth dataset (i.e., quadruple collocation or QC) and partially address the independent assumption to calculate a part of error cross-correlation (Vogelzang and Stoffelen, 2021). To combine the benefits of both double and quadruple collocation, (Dong et al., 2020b) recently proposed the extended double instrumental or EIVD.

In this study, we proposed a collocation-based data ensembled method to merge multiple ET products and produced the collocation-analyzed multi-source ensembled land evapotranspiration data, abbreviated as CAMELE. Merging framework was validated through synthetic experiments and validation against flux tower observations. By minimizing mean square error, the optimal weights for inputs were given using collocation-based evaluation results. Finally, our merged product was 
95 compared at point and global scale with others.

\section{2. Data}

97 Five widely used land ET products were selected, covering the period from 1980 to

98 2020. In addition, in-situ observations were employed for evaluation of the

99 framework and further comparison of our merged product. The spatial and temporal

100 resolutions of input datasets are shown in the following Table:

101 TABLE.1 Summary of products involved

\begin{tabular}{|c|c|c|c|c|c|}
\hline Name & Schemes & $\begin{array}{c}\text { Spatial } \\
\text { resolution }\end{array}$ & $\begin{array}{l}\text { Temporal } \\
\text { resolution }\end{array}$ & Time Span & Reference \\
\hline ERA5 & IFS & $0.1^{\circ} \& 0.25^{\circ}$ & Hourly & $\begin{array}{c}1980- \\
\text { present }\end{array}$ & $\begin{array}{l}\text { (Hersbach } \\
\text { et al., 2020) }\end{array}$ \\
\hline GLDASv2.1 & Noah & $0.25^{\circ}$ & Daily & $1980-2019$ & $\begin{array}{l}\text { (Rodell et } \\
\text { al., 2004) }\end{array}$ \\
\hline PMLV2 & Penman-Monteith-Leuning & $0.083^{\circ}$ & 8-Daily & $2002-2019$ & $\begin{array}{l}\text { (Zhang et } \\
\text { al., 2019) }\end{array}$ \\
\hline FLUXCOM & Machine learning & $0.083^{\circ}$ & 8-Daily & $2001-2013$ & $\begin{array}{c}\text { (Jung et al., } \\
2019 \text { ) }\end{array}$ \\
\hline GLEAMv3.3a & Priestley-Taylor & $0.25^{\circ}$ & Daily & $1980-2017$ & $\begin{array}{l}\text { (Miralles et } \\
\text { al., 2011) }\end{array}$ \\
\hline
\end{tabular}

103 (1) ERA5

104 The European Centre for Medium-Range Weather Forecasts (ECMWF) provides

105 ERA5-Land global hourly reanalysis dataset at various resolutions, covering the

106 period 1981 to nearly present. ERA5-Land has been produced by replaying the land

107 component of ECMWF ERA5 climate reanalysis. The atmospheric forcing data

108 served an indirect influence as the constraint of the model-based estimates (Hersbach

109 et al., 2020). Land evaporation is just one of the many output variables, which

110 containing evaporation from bare soil, evaporation from open water surface excluding

111 oceans, evaporation from the top canopy, evaporation from vegetation transpiration,

112 snow evaporation, potential evaporation, and total evaporation. The dataset is freely

113 available at the Climate Change service of Copernicus center

114 (http://cds.climate.copernicus.eu). The accumulated total evaporation was

115 downloaded and aggregated from hourly to daily timestep over $0.1^{\circ}$ and $0.25^{\circ}$ 
116 resolutions in this study.

\section{7 (2) GLDASv2.1 Noah}

118 The Global Land Data Assimilation System (GLDAS) product is a land surface

119 simulation forced by a combination of model and observation datasets, which incorporates advanced and sophisticated data assimilation methodologies (Rodell et

121 al., 2004). GLDAS runs multiple land surface models (LSMs), including Noah,

122 Mosaic, Variable infiltration capacity (VIC) and Community land model (CLM).

123 These combined models provide global estimation of evapotranspiration at both fine

124 and coarse spatial $\left(0.01^{\circ}\right.$ and $\left.0.25^{\circ}\right)$ and temporal (3-hourly and monthly) resolution.

125 More complicated descriptions of the GLDAS products are available at NASA's

126 Hydrology Data and Information Services Center

127 (http://disc.sci.gsfc.nasa.gov/hydrology). In this study, we employed the GLDAS 2.1

128 Noah model at $0.25^{\circ}$ spatial resolution with 3-hourly frequency. The 3-hourly data

129 were then aggregated to daily timestep to match the consistence with other products.

\section{0 (3) PMLV2}

131 The Penman-Monteith-Leuning model version 2 global evaporation (PMLV2) is

132 produced based on Penman-Monteith-Leuning model (Zhang et al., 2019). The PML

133 model was first proposed by (Leuning et al., 2008), and further improved by (Zhang

134 et al., 2010). The PML version 1 (PMLv1) is based on a biophysical model that

135 considers canopy physiological processes and soil evaporation for the accurate

136 estimation of surface conductance $\left(G_{s}\right)$, which is the focus of PM-based method. It

137 was further incorporated with a canopy conductance $\left(G_{c}\right)$ model that coupled

138 vegetation transpiration with gross primary productivity, resulting in the PML version

1392 (PMLv2) (Gan et al., 2018). (Zhang et al., 2019) applied the PMLv2 model at global

140 scale. The daily inputs include: (1) leaf area index (LAI), white sky shortwave albedo,

141 and emissivity from Moderate Resolution Imaging Spectroradiometer (MODIS); (2)

142 temperature variables $\left(T_{\max }, T_{\min }, T_{a v g}\right)$, instantaneous variables $\left(P_{s u r f}, P_{a}, U, q\right)$, and

143 accumulated variables $\left(P_{r c p}, R_{l n}, R_{s}\right)$ from GLDAS. The evaporation is divided into

144 direct evaporation from bare soil $\left(E_{s}\right)$, evaporation from solid water (water body, 
145 snow, and ice) $\left(E T_{\text {water }}\right)$, and vegetation transpiration $\left(E_{c}\right)$. The PMLv2-ET is well-

146 calibrated against 8-daily eddy covariance data from 95 global flux towers for ten

147 land cover types (Kong et al., 2020). The data is freely available at the data center of

148 institute of Tibetan Plateau Research, Chinese Academy of Sciences via application

149 (https://data.tpdc.ac.cn/zh-hans/data/48c16a8d-d307-4973-abab-972e9449827c/?q=).

150 In this study, the 8-daily PMLv2 data were used and interpolated to $0.1^{\circ}$ using the

151 MATLAB Gaussian process regression package. The accumulated total evaporation is

152 calculated as:

$$
E T=E_{s}+E_{c}+E T_{\text {water }}
$$

154 Data with abnormal value were removed.

\section{5 (4) FLUXCOM}

156 FLUXCOM is a machine-learning-based merging data of global land-atmosphere

157 energy fluxes, which is the combination of remote sensing data and meteorological data (Jung et al., 2019). FLUXCOM uses several machine-learning-based regression tools, including tree-based methods, regression splines, neural networks, and kernel methods. The outputs were designed following two complementary strategies: (1)

161 FLUXCOM-RS: merging exclusively remote sensing data to produce flux data with high spatial resolution. (2) FLUXCOM-RS+METEO: merging meteorological observations with remote sensing data at daily temporal resolution. The exclusive ensemble of RS data allows for generating gridded flux products at $500 \mathrm{~m}$ spatial resolution, with relatively low frequency of 8-daily. Additionally, the FLUXCOM-RS

166 data only cover the period after 2000 due to data availability. While the merging of meteorological data and remote sensing data extended the coverage (since 1980) with the cost of relatively coarser spatial resolution $\left(0.5^{\circ}\right)$. More detailed descriptions of the FLUXCOM dataset are available on the FLUXCOM website (http://fluxcom.org/).

170 Data is freely available via contact.

171 In this study, we employed the FLUXCOM-RS 8-daily $0.0833^{\circ}$ energy flux data and 172 convert the latent heat to evaporation using ERA5-Land aggregated daily air 173 temperature. The conversion follows the equation: 


$$
E T=\frac{L E \times 30 \times 60}{(2.501-0.002361 \times T) \times 10^{6}}
$$

175 Where $E T$ is the evapotranspiration $\left(\mathrm{kg} \cdot \mathrm{m}^{-2} \cdot \mathrm{s}^{-1}\right), L E$ is the latent heat flux (W

$\left.176 \mathrm{~m}^{-2}\right), T$ is the air temperature $(K)$. Furthermore, the original evaporation data were

177 interpolated to $0.1^{\circ}$ using the MATLAB Gaussian process regression package.

\section{$178 \quad$ (5) GLEAM v3.3a}

179 In this study, the Global Land Evaporation Amsterdam Model version 3.3a (GLEAM 180 v3.3a) dataset (Miralles et al., 2011; Martens et al., 2017) at $0.25^{\circ}$ are used. This

181 version of GEAM provides daily estimation of actual evaporation $(E)$, bare soil 182 evaporation $\left(E_{b}\right)$, canopy interception $\left(E_{i}\right)$, transpiration from vegetation $\left(E_{t}\right)$, 183 potential evaporation $\left(E_{p}\right)$, and snow sublimation $\left(E_{S}\right)$ for the period 2003-2018. The 184 data is freely available on VU university Amsterdam Geoservices website 185 (http://geoservices.falw.vu.nl).

186 GLEAM is based on the Priestley-Taylor framework (Priestley and Taylor, 1972), 187 which employs reanalysis temperature and radiation to estimate potential ET (PET).

188 Furthermore, the PET is reduced to actual ET using remotely sensed soil moisture and 189 vegetation optical-depth measurements. The GLEAM AET data was validated at 43 190 FLUXNET flux sites and had been proven to provide solid AET estimation (Majozi et 191 al., 2017). Since ERA5-Land and GLEAMv3.3a both employ the ECMWF 192 atmospheric reanalysis data, they may suffer the uncertainty from the same origin. 193 However, due to the indirect influence of atmospheric data used in ERA5-Land, we 194 can still assume that these two products are independent.

\section{5 (6) In-situ observations}

196 The FLUXNET2015 Tier 1 (http://fluxnet.fluxdata.org/) half-hourly eddy-covariance 197 data are used in our study (Pastorello et al., 2020). After data filtering and processing, 19882 sites are selected, and the observations are aggregated to daily timestep as 199 reference data for evaluation of other products.

200 Following a filtering process by (Lin et al., 2019; Li et al., 2019), original hourly data 201 is selected. Firstly, only the measured and good-quality gap-filled data are used for 202 quality control. Secondly, to reduce the impact of canopy interception (Medlyn et al., 
203 2017; Knauer et al., 2018), we excluded days with rainfall, as well as one extra 204 subsequent day after rainy events. Thirdly, data records with negative GPP, ET and

205 VPD were removed. When the number of valid half-hourly observations is higher 206 than 38 (about $80 \%$ ) per day, the daily total ET is calculated as:

$$
E T_{i}=\frac{E T=\frac{\sum_{i=1}^{N}\left(E_{i} \times 48\right)}{N}}{L E_{i} \times 30 \times 60}
$$

209 Where $N$ is the number of valid half-hourly observations; $L E_{i}$ is the half-hourly

210 observed latent heat flux $\left(\mathrm{W} \cdot \mathrm{m}^{-2}\right) ; T_{i}$ is the air temperature $(\mathrm{K})$.

211 If the number of valid data is below 38 , the daily value is set as fill value.

212 Additionally, previous studies illustrated that FLUXNET2015 data suffered from an

213 energy imbalance problem. Thus, following the method proposed by (Twine et al.,

214 2000), the measured ET data are corrected. The sites are distributed globally, mostly

215 located in North America and Europe. The International Geosphere-Biosphere

216 Program (IGBP) land cover classification system (Loveland et al., 1999) is employed

217 to distinguish the nine PFTs across sites, including evergreen needleleaf forests (ENF),

218 evergreen broadleaf forests (EBF), deciduous broadleaf forests (DBF), croplands

219 (CRO), grasslands (GRA), savannas (SAV), woody savannas (WSA), and mixed

220 forests (MF). The selected sites cover the period from 2003 to 2017 and each has at

221 least 3 years of reliable data. Detailed information are included in the Appendix.

\section{3. Method}

223 In our study, the merging process contained three steps: (1) uncertainty 224 characterization of inputs using collocation analysis methods; (2) calculation of 225 optimal weights for each product by minimizing the mean square error; (3) linear 226 combination of inputs and products of merged product over various resolutions. 227 Figure 1 represents the general process for data merging. 


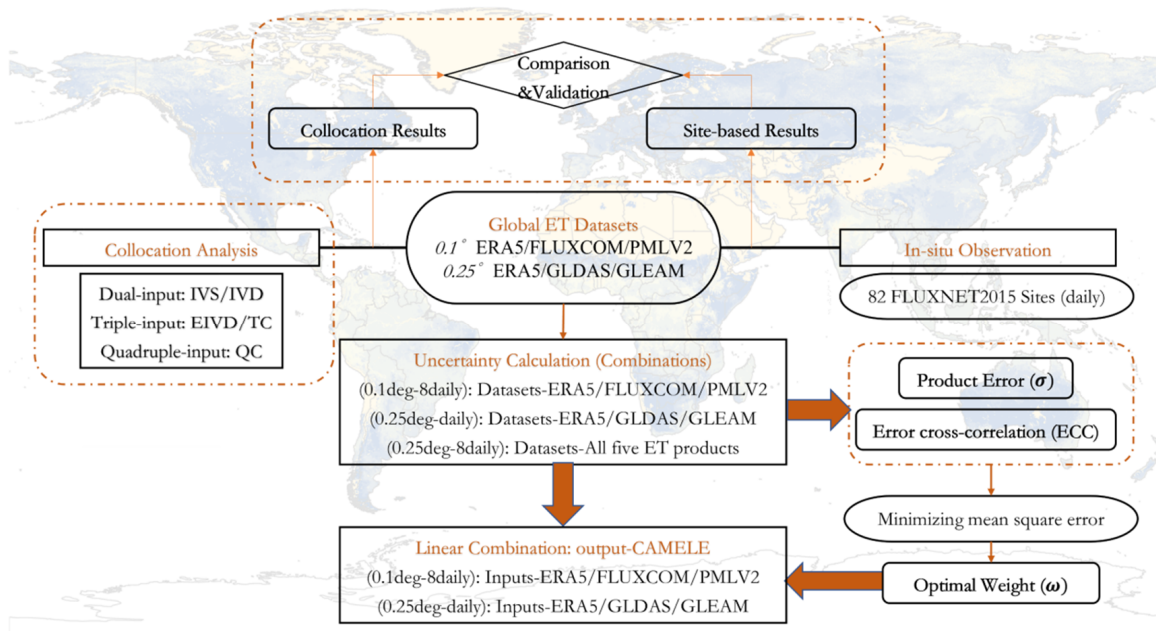

FIGURE.1 A flowchart for the data merging process

\subsection{Uncertainty characterization}

The challenge for the evaluation of global ET products is due to the lack of reliable benchmark. While the main advantage of collocation analysis methods is that no reference is required. In collocation analysis, independent products of a geophysical variable are typically assumed to be linearly related to the true signal (Mccoll et al., 2016). This linear model can be expressed as:

$$
x=\beta_{x} P+B_{x}+\varepsilon_{x}
$$

Where $x$ is the product, $P$ is the true signal; $\beta_{x}$ and $B_{x}$ are the ordinary least squares intercept and slope; and $\varepsilon_{x}$ is zero-mean random error. This model is referred as the additive error structure model, while in practice, multiplicative error model in conjunction log transformation is more preferred (Li et al., 2018).

The basic assumptions adopted in collocation contain: (1) error orthogonality, assuming that the random error is independent with the true signal, which can be expressed as: $C_{P \varepsilon}=\overline{P \varepsilon}-\bar{P} \bar{\varepsilon}=0$; (2) zero error cross-correlation, requiring the independence of each two products, which can be expressed as: $\overline{\varepsilon_{x} \varepsilon_{y}}=\overline{\varepsilon_{y} \varepsilon_{z}}=$ $\overline{\varepsilon_{x} \varepsilon_{z}}=0$; (3) the random error of each products is zero-mean, which means $\bar{\varepsilon}=0$. 
246 Based on these assumptions, the covariances between the products and the Pearson

247 correlation $\left(R^{2}\right)$ of each product against the true signal can be solved.

248 The triple-collocation method (TC) requires a triplet of independent data sources

249 (Stoffelen, 1998; Gruber et al., 2020) .The collocation analysis relies highly on the

250 assumption that all datasets are mutually independent, which means error cross-

251 correlation (ECC) is considered as zero (Gruber et al., 2020). As illustrated by

252 (Yilmaz and Crow, 2014), the violation of zero ECC assumption usually results in

253 underestimation of data errors. However, it is usually difficult to find three

254 independent datasets in practice. To address the problem, (Su et al., 2014) proposed

255 the instrumental-variable based approach by using a temporally lag-1 time series of

256 one product as the third independent product, which only requires double collocation

257 and is referred as single instrumental variable algorithm, or IVS. Based on that, (Dong

258 et al., 2019) achieved a more robust solution, denoted as double instrumental variable

259 algorithm, or IVD. (Gruber et al., 2016) extends the original algorithm to include a

260 fourth dataset (i.e., quadruple collocation or QC) and partially address the

261 independent assumption to calculate a part of ECCs (Vogelzang and Stoffelen, 2021).

262 To combine the benefits of both double and quadruple collocation, (Dong et al.,

263 2020b) recently proposed the extended double instrumental (EIVD), by which an

264 ECC can be estimated using three datasets. Detailed deviations of each method were

265 included in the Appendix.

266 To characterize the uncertainties of inputs, all five collocation analysis methods were

267 employed at both $0.1^{\circ}$ and $0.25^{\circ}$, daily and 8-daily resolution. Different methods can

268 also be categorized by number of inputs: (1) Dual inputs (IVS/IVD); (2) Triple inputs

269 (TC/EIVD); (3) Quadruple inputs (QC). For dual-input methods, IVS required the

270 selection of product to derive the lag-1 series as the third input, while IVD used the

271 lag-1 variances of both products. For triple-input methods, EIVD required the

272 identification of two products with non-zero error-correlation-covariance, while TC

273 assumed all three products were mutual-independent. For quadruple-input method, the 
274 requirement of QC was the same as EIVD. Therefore, taken the combinations over

$2750.25^{\circ} / 8$-daily resolution for example, the number of combination scenarios for: (1)

276 IVS: $\left(\begin{array}{l}5 \\ 2\end{array}\right) \times\left(\begin{array}{l}2 \\ 1\end{array}\right)=20$; (2) EIVD: $\left(\begin{array}{l}5 \\ 3\end{array}\right) \times\left(\begin{array}{l}3 \\ 2\end{array}\right)=30$; (3) QC: $\left(\begin{array}{l}5 \\ 4\end{array}\right) \times\left(\begin{array}{l}4 \\ 2\end{array}\right)=30$. Detailed

277 description of combinations could be found in the Appendix.

\section{$278 \quad 3.2$ Calculation of Optimal Weights}

279 Given specific variances of inputs, linear combination could serve as a simple and 280 efficient solution for data assimilation. In this study, each product is assigned with the optimal weight $(\omega)$ that minimizing the mean square error (Bates and Granger, 1969;

282 Kim et al., 2020) using error variances $\left(\sigma_{\varepsilon_{i}}\right)$ and the $\operatorname{ECC}\left(\sigma_{\varepsilon_{i} \varepsilon_{j}}\right)$ as:

$$
\omega_{i j}=\frac{\sigma_{\varepsilon_{i}}^{2}-\sigma_{\varepsilon_{i} \varepsilon_{j}}^{4} \sigma_{\varepsilon_{i}} \sigma_{\varepsilon_{j}}}{\sigma_{\varepsilon_{i}}^{2}+\sigma_{\varepsilon_{j}}^{2}-2 \sigma_{\varepsilon_{i} \varepsilon_{j}}^{4} \sigma_{\varepsilon_{i}} \sigma_{\varepsilon_{j}}}
$$

And the combined product $\theta_{c}$ is calculated as:

$$
\theta_{c}=\sum_{i=1}^{N} \theta_{i} \omega_{i}
$$

Where $\omega_{i}$ is the weighted arithmetic mean for each product, for a dual-input combination, the value of $\omega_{i}$ is calculated as:

$$
\omega_{i}=\frac{\omega_{i j}}{\omega_{i j}+\omega_{j i}}
$$

For a triple-input combination, the value of $\omega_{i}$ is given as:

$$
\omega_{i}=\frac{\omega_{i j}+\omega_{i k}}{\left(\omega_{i j}+\omega_{i k}\right)+\left(\omega_{j i}+\omega_{j k}\right)+\left(\omega_{k i}+\omega_{k j}\right)}
$$

In addition, for a quadruple-input, the value is:

$$
\omega_{i}=\frac{\omega_{i j}+\omega_{i k}+\omega_{i m}}{\left(\omega_{i j}+\omega_{i k}+\omega_{i m}\right)+\left(\omega_{j i}+\omega_{j k}+\omega_{j m}\right)+\left(\omega_{k i}+\omega_{k j}+\omega_{k m}\right)+\left(\omega_{m i}+\omega_{m j}+\omega_{m k}\right)}
$$

\subsection{Merging combination}

294 The data were produced over $0.1^{\circ}$-8Daily and $0.25^{\circ}$-Daily resolutions based on

295 evaluation results using IVD and EIVD algorithms. The selection of algorithm was 
296 based on the comparison results. The performance of IVD and EIVD generally

297 outperformed other methods at chosen resolutions. In this study, each product is

298 assigned with the optimal weight $(\omega)$ that minimizing the mean square error (Bates

299 and Granger, 1969; Kim et al., 2020) using collocation-evaluated error variances $\left(\sigma_{\varepsilon_{i}}\right)$

300 and the ECC $\left(\sigma_{\varepsilon_{i} \varepsilon_{j}}\right)$. The table below showed the data used for merging during

301 different period.

302

TABLE.2 Combination of inputs and accessible methods

\begin{tabular}{ccc}
\hline & Scenario 1 (0.1 ${ }^{\circ}$-8Daily) & \\
\hline Time Period & Available Products & Method \\
$(2001.01 .01-2002.07 .03)$ & ERA5/ FLUXCOM & IVD \\
$(2002.07 .04-2013.12 .27)$ & ERA5/ FLUXCOM/ PMLV2 & EIVD \\
$(2013.12 .28-2019.08 .29)$ & ERA5/ PMLV2 & IVD \\
\hline Scenario 2 (0.25 ${ }^{\circ}$-Daily) & Method \\
\hline Time Period & Available Products & IVD \\
$(1981.01 .01-2003.02 .01)$ & ERA5/ GLEAM & EIVD \\
$(2003.02 .02-2018.12 .31)$ & ERA5/ FLUXCOM/ PMLV2 & IVD \\
\hline
\end{tabular}

\section{Validation of framework}

304 In this section, the validation of our framework was conducted as follow: (1) synthetic

305 experiments were design to validate the merging route and provide information for the

306 selection of proper collocation methods; (2) collocation-based evaluation results for inputs were compared against site-based evaluation using FLUXNET. Here, we used

308 three indexes for comparison, including:

309 Pearson's Correlation $\left(R^{2}\right)$

$$
R^{2}=\frac{\left[\sum\left(S_{i}-\bar{S}\right)\left(R_{i}-\bar{R}\right)\right]^{2}}{\sum\left(S_{i}-\bar{S}\right)^{2} \sum\left(R_{i}-\bar{R}\right)^{2}}
$$


313 Standard Deviation $(S D)$

$$
S D=\sqrt{\frac{\sum\left(x_{i}-\bar{x}\right)^{2}}{N}}
$$

\section{$315 \quad 4.1$ Synthetic validation}

316 In our study, five synthetic experiments were designed to evaluate the merging route

317 and compare different collocation analysis algorithms. Our aims were to (1)

318 demonstrate that the merging data using linear combination based on minimizing

319 mean square error outperforms any of the parent products; (2) compare the

320 improvement of merging data over parent products using optimal weights derived by

321 different methods; (3) evaluate how the violation of assumptions will impact the

322 results; (4) illustrate that even though the assumptions are not perfectly valid, the

323 merging product is still improved. Each experiment was repeated 1000 times using

324 bootstrap to reduce the inherent uncertainty. In addition, only multiplicative error

325 structure was employed in our experiments due to its applicability on collocation error

326 characterization (Li et al., 2018; Gruber et al., 2020).

\section{4.1.1 Design of synthetic experiment}

328 A true signal $(t)$ was generated following a passion distribution with a sample size of

$329 N: t=0.85 P(0 \sim 50, N)$ (Kim et al., 2020). Then a collection of synthetic products, $\theta_{i}(i=1,2,3$, and 4$)$, was generated by adding zero-mean Gaussian errors $\left(\varepsilon_{i}\right)$ to $t$ as:

$$
\theta_{i}=t+\varepsilon_{i}
$$

332 This synthetic model was employed for the five synthetic experiments, where each

333 assumption was violated one at a time by generating a relative error $\left(\varepsilon_{i}\right)$. In addition,

334 six value of signal-to-noise rations $\left(S N R_{d B}=0.1,0.5,1,2,5\right.$, and 10) were adopted

335 for the consideration of various noise range in the five synthetic experiments as: 


$$
S N R=10^{\frac{S N R_{d B}}{10}}, P_{n}=\frac{P_{t}}{S N R}
$$

337 Where $P_{t}$ and $P_{n}$ are signal power and noise power, respectively. While $P_{n}$ is used to

338 generated noise with a specific variance according to the given SNR.

339 The first experiment (denote as "Exp1") was mean to test how the sample size $(N)$

340 affects the result. Here, six sample sizes were chosen $(50,200,600,1000,5000$, and

341 10000) and the errors were expressed as:

$$
\varepsilon_{i}=N\left(0, P_{n}\right)
$$

343 Where $N\left(0, P_{n}\right)$ represents the Gaussian distribution with zero mean and variance of $344 P_{n}$.

345 The second experiment (denoted as "Exp2") was designed to analyze the violation of 346 stationary assumption that random error of each product was assumed to be zero347 mean. Here, we increased the error mean by linearly including an additive term as:

$$
\varepsilon_{i}=a+\frac{H-0.5 N}{N} \times s \times E[t], H=1: L
$$

349 Where $a$ is the random error generated using Gaussian distribution $\left(N\left(0, P_{n}\right) ; H\right.$ is the 350 monotonical increment ranging from 1 to $N ; s$ is the increasing slope with relation to 351 the exception of true signal. The sample size is fixed as 800 for Exp2 and the 352 remaining experiments based on the analysis from Exp1.

353 The third experiment (denoted as "Exp3") aimed to evaluate the impact of the 354 violation of zero error correlation covariance assumption. Non-zero ECC indicated 355 that products were not mutual-independent. Here, we considered two conditions: (1) 356 fully correlated, where all products were dependent; (2) partly correlated, where only two products were related. Given that IVS and IVD algorithms only require two 358 products, evaluations of dual-input methods were all under fully correlated consideration. The errors were defined as:

$$
\text { partly correlated: }\left\{\begin{array}{c}
\varepsilon_{1 \sim 3}=a=N\left(0, P_{n}\right) \\
\varepsilon_{4}=\sigma_{\varepsilon_{1} \varepsilon_{4}} \varepsilon_{1}+\sqrt{1-\sigma_{\varepsilon_{1} \varepsilon_{4}}^{2}} a
\end{array}\right.
$$




$$
\text { fully correlated: }\left\{\begin{array}{c}
\varepsilon_{1}=a=N\left(0, P_{n}\right) \\
\varepsilon_{2 \sim 4}=\sigma_{\varepsilon_{1} \varepsilon_{2 \sim 4}} \varepsilon_{1}+\sqrt{1-\sigma_{\varepsilon_{1} \varepsilon_{2 \sim 4}}^{2}} a
\end{array}\right.
$$

362 Where $\sigma_{\varepsilon_{i} \varepsilon_{j}}$ is the error correlation covariance (ECC) and set as varying values $(0.1$,

$3630.2,0.4,0.6,0.8$, and 0.9 ).

364 The fourth experiment (denoted as "Exp4") tested how the combination results were

365 changed when the error-truth orthogonality assumption was violated. The errors in

366 Exp4 were derived as:

$$
\varepsilon_{i}=\sigma_{\varepsilon_{i}} \times \frac{t}{\sqrt{S N R}}+\sqrt{1-\sigma_{\varepsilon_{i}}^{2}} a
$$

368 Where $\sigma_{\varepsilon_{i} t}$ is the cross correlation between error and true signal and set as varying values $(0.1,0.2,0.4,0.6,0.8$, and 0.9$)$.

The last experiment (denoted as "Exp5") investigated the effects of violation on zero

371 autocovariance assumption. This assumption was adopted in IVS, IVD, and EIVD algorithms. The error of the one synthetic data was generated by a first-order autoregressive process with varying autocorrelation coefficients $(0.1,0.2,0.4,0.6,0.8$, and 0.9) using MATLAB simulation package.

$$
\varepsilon_{i}=\operatorname{simulate}\left(\left[A R\left({ }^{\prime} \text { Constant }^{\prime}, \bar{t}^{\prime}, A R^{\prime}, \rho_{\text {lag }},{ }^{\prime} \text { Variance }^{\prime}, P_{n}\right)\right], N\right)
$$

376 Where $\bar{t}$ is the expectation of true signal; $\rho_{\text {lag }}$ is the autocorrelation coefficient.

377 In summary, the designed aim and control parameter of each experiment is shown 378 below:

TABLE.3 Description of synthetic experiments

\begin{tabular}{ccc}
\hline No. & Related Assumption & Control Parameter \\
\hline Exp0 & Error noise & Signal-to-noise ratios $\left(S N R_{d B}\right)$ \\
Exp1 & Sample representative & Sample Size $(N)$ \\
Exp2 & Stationarity & Non-stationary slope $(s)$ \\
Exp3 & Zero Error correlation covariance & Error-cross-correlation $\left(\rho_{\varepsilon_{i} \varepsilon_{j}}\right)$ \\
Exp4 & Zero Error-truth orthogonality & Error-truth cross-correlation $\left(\sigma_{\varepsilon t}\right)$ \\
Exp5 & Zero Error autocorrelation & Error autocorrelation $(\rho)$ \\
\hline
\end{tabular}


https://doi.org/10.5194/essd-2021-456

Preprint. Discussion started: 1 March 2022

(c) Author(s) 2022. CC BY 4.0 License.

\section{$380 \quad$ 4.1.2 Synthetic Experiments Results}

381 The synthetic results were validated based on the data-truth correlation $\left(\rho_{\theta_{c} t}\right)$. Given

382 that the synthetic data could not explicitly reflect the real situation, the analysis of

383 results should focus on patterns and tendencies with changes in control parameters.

384 Here, we focused on the improvement of combined product based on $\Delta \rho$ :

$$
\Delta \rho=\rho_{\theta_{c} t}-\max \left[\rho_{i t}\right]
$$

386 Here, positive $\Delta \rho$ represents improvements of the combined product, and vice versa.

387 The analysis is twofold: (1) the results of all experiments under 0.1dB SNR are

388 investigated; (2) the results of EIVD-based experiments under six SNR value are

389 compared to illustrate the impact of noise. 

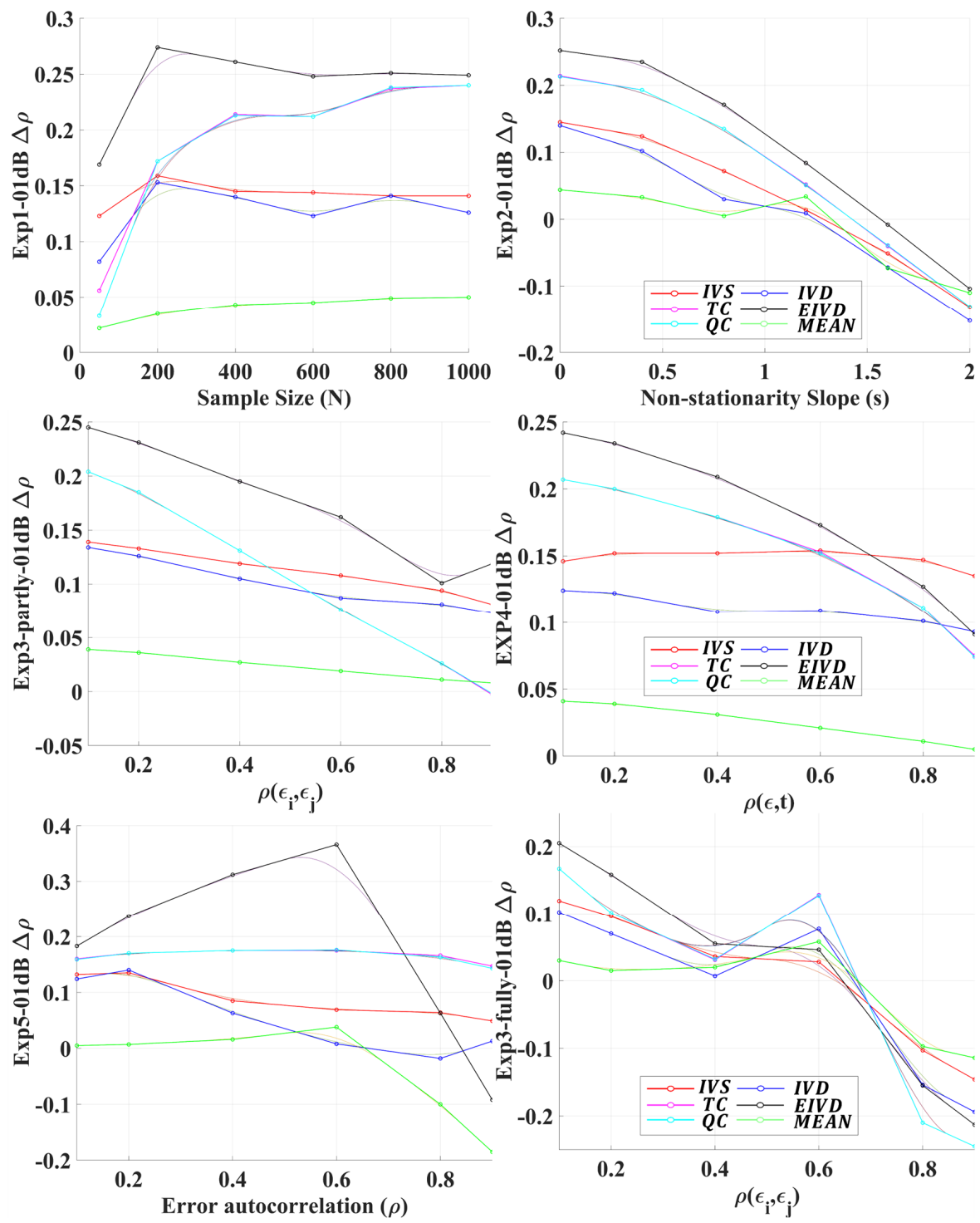

FIGURE.2 Results of all synthetic experiments with $0.1 \mathrm{~dB}$ SNR. All methods were control parameter. The legend of y axis in all figures is the $\Delta \rho$. Lines in various colors corresponds to a method as marked in the legend box.

395 In Exp1, the value of $\Delta \rho$ raised with increasing sample size, while the variability reduced. Combined products based on all method present improvement, while EIVDbased product outperformed others. The expansion of data volume effectively reduced 
398 the uncertainty. Moreover, the results suggested that a sample size no less than 800

399 should be used for the combination.

400 Exp2 was designed to test the impact of stationarity assumption with increasing slope

401 of error mean $(s)$. With the augment of slope, performance of combined product 402 based on all method turned down, including the simplest average method. When the 403 slope was over 1.0, the combined products showed no improvement. However, this 404 value of slope $(s>1)$ indicated that the expectation of random error was one time 405 greater than the mean of true signal, which was hardly possible in practice.

406 In Exp3, we compared the results under two different conditions: (1) fully correlated, 407 where all products were dependent; (2) partly correlated, where only two products 408 were related. The value of $\Delta \rho$ rapidly decreased with the augment of $\rho_{\varepsilon_{i} \varepsilon_{j}}$ under both 409 conditions. When all products were correlated, the decreasing slope of $\Delta \rho$ was significantly steeper. Since zero-ECC assumption was hard to meet in practical 411 situation, the finding suggested that the ECC should be carefully considered for a 412 linear combination, as mentioned in previous studies (Gruber et al., 2020). In addition, 413 the impact of ECC on combination was relatively lower under partly correlated 414 condition. Thus, the selection of products was also essential for error characterization 415 and combination.

416 The impact of error-truth orthogonality assumption was shown in Exp4. The 417 improvement in $\Delta \rho$ was weakening when the true signal was more relevant with the 418 random error. When the correlation $(\rho)$ was over 0.9 , which indicated that random error was highly correlated with true signal, the improvement in $\Delta \rho$ was nearly zero.

420 However, given that the random error of data was usually considered independent 421 with true signal in practice, the impact of error-truth orthogonality could not the main 422 source of the method uncertainty (Yilmaz and Crow, 2014).

423 As for Exp5, we designed this experiment to investigate the impact of autocovariance.

424 This assumption is related to IVS, IVD, and EIVD methods. The overall combination 425 performance in $\Delta \rho$ declined compared with other experiments, and the value of $\Delta \rho$ 
426 was slightly degraded when the error autocorrelation $(\rho)$ became significant. The 427 finding suggested that the consideration of error autocorrelations of products was 428 necessary. However, evapotranspiration was less influenced by predominant condition 429 (Zhang et al., 2011; Sharma et al., 2021). Thus, the impact of error-autocorrelation 430 should not introduce much uncertainty.

431 Finally, comparing different methods, the results demonstrated that combination 432 performance based on EIVD method generally outperformed other methods through 433 synthetic experiments. As for the simplest averaging method, though previous studies 434 recommended the average value as the proxy of reference (Pan et al., 2020; Burnett et 435 al., 2020; Baker et al., 2021), our synthetic results demonstrated that the averaging 436 method presented the lowest improvement. For gridded data, the equal weight for 437 each grid assigned by averaging method ignored the spatial variability of different 438 products, which could result in large uncertainty. In addition, since EIVD algorithm 439 used the lag-1 series of two products, the violation of zero-error-autocorrelation 440 assumption had the greatest impact than other methods. 

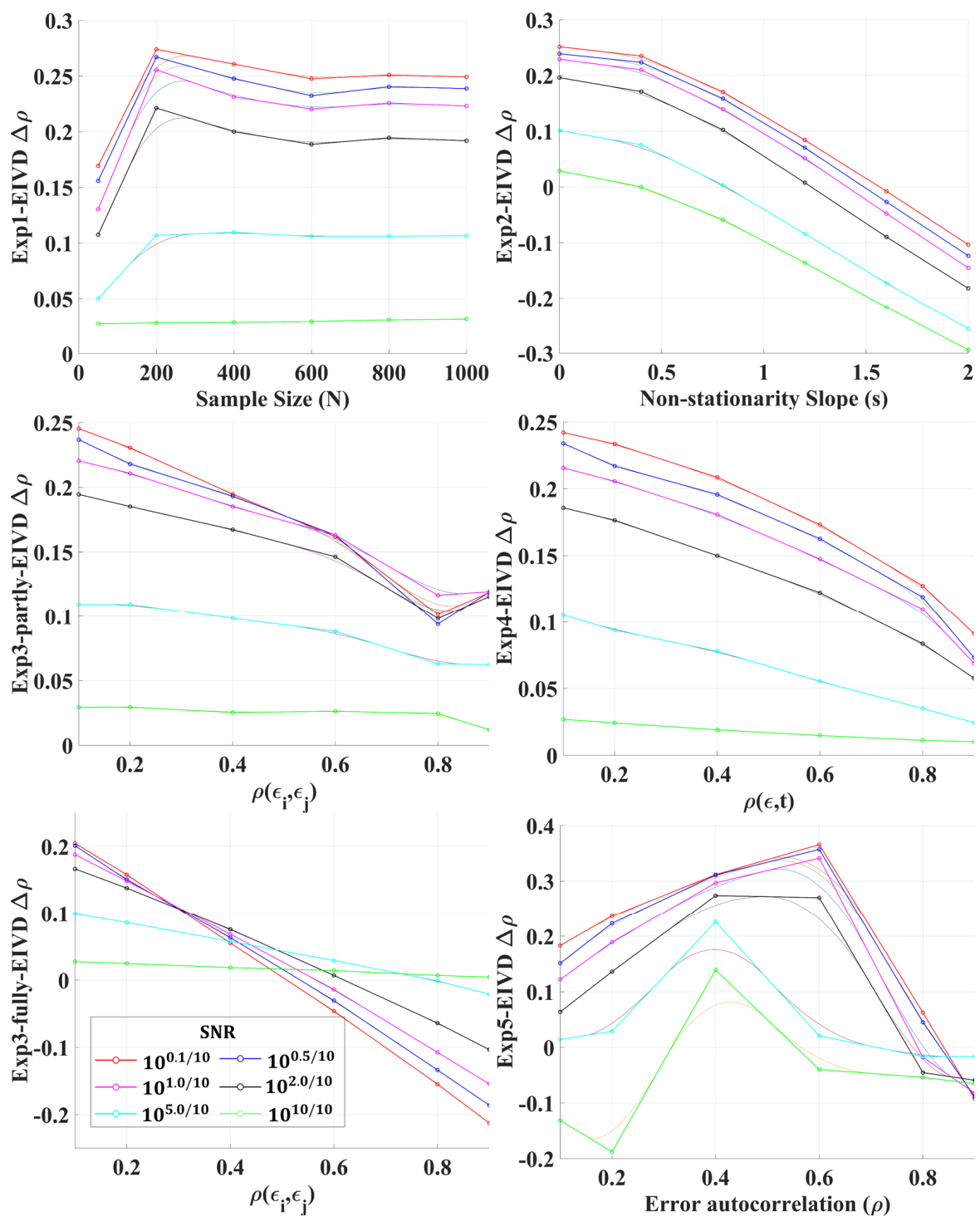

FIGURE.3 EIVD-based results of all synthetic experiments under six various SNR

value to investigate the impact of error noise. The legend of $\mathrm{x}$ axis in each figure represents the control parameter. The legend of y axis in all figures is the $\Delta \rho$. Lines in various colors corresponds to a SNR value as marked in the legend box.

446 As shown in the figure, when the $S N R_{d B}$ was over 1, the combination performance was dramatically degraded. The results illustrated that impact of noise was significant 448 and was necessary to be taken into consideration. In practice, the $S N R_{d B}$ is usually 
449 considered between 0.1 and 0.6 for products of geographical variables (Biscarini et al., $450 \quad 2021)$.

$451 \quad 4.2$ Site-based Validation of collocation-based evaluation results

452 Flux tower observation is the direct way to achieve the value of evapotranspiration, 453 which is usually regarded as the reference for the assessments of products (Decker et 454 al., 2012; Griebel et al., 2020). Due to the high cost for installation and maintenance 455 of flux tower, the distribution and data period is scare at global scale. To prove that 456 collocation analysis methods could be used as a reliable alternative when direct 457 observations are not available, we compared the collocation-based evaluation results 458 (as simulation) against the results based on flux tower observations (as reference). 459 The comparisons were conducted over three resolutions: $0.1^{\circ}$-8Daily, $0.25^{\circ}$-Daily, 460 and $0.25^{\circ}-8$ Daily.

461 Table 4 presents the average value of Pearson's correlation $\left(R^{2}\right)$ for five collocation 462 analysis methods under all scenarios using multiplicative error structure. The 463 comparison results demonstrated that collocation framework was reliable for the evaluation of ET products. Among the methods, IVD, EIVD, and QC were the three 465 preferred methods for usage.

466 TABLE.4 Pearson's correlation $\left(R^{2}\right)$ for different products using collocation analysis 467 algorithms against evaluations based on in-situ observations.

\begin{tabular}{ccccccc} 
& \multicolumn{3}{c}{ Resolution: $\mathbf{0 . 1}$ /8Daily } & \multicolumn{3}{c}{ Resolution: $\mathbf{0 . 2 5}^{\circ}$ /Daily } \\
\cline { 2 - 7 } Methods & ERA5 & FLUXCOM & PMLV2 & ERA5 & GLEAM & GLDAS \\
\hline IVS & 0.682 & 0.357 & 0.442 & 0.574 & 0.486 & 0.616 \\
IVD & 0.647 & 0.663 & 0.669 & 0.576 & 0.693 & 0.700 \\
TC & 0.712 & 0.035 & 0.574 & 0.649 & 0.645 & 0.691 \\
EIVD & 0.698 & 0.719 & 0.703 & 0.751 & 0.692 & 0.719 \\
\hline & \multicolumn{5}{c}{ Resolution: 0.25\%/8Daily } \\
Methods & ERA5 & FLUXCOM & PMLV2 & GLEAM & GLDAS \\
\hline IVS & 0.699 & 0.542 & 0.523 & 0.675 & 0.686 \\
IVD & 0.683 & 0.643 & 0.546 & 0.631 & 0.693 \\
TC & 0.734 & 0.803 & 0.710 & 0.564 & 0.764 \\
EIVD & 0.717 & 0.722 & 0.608 & 0.800 & 0.748 \\
QC & 0.743 & 0.529 & 0.570 & 0.489 & 0.766 \\
\hline
\end{tabular}


469 graphically summarizing how closely the results match the reference. The similarity is 470 quantified in terms of their correlation, their centered root-mean-square difference, 471 and the amplitude of their variations (represented by their standard deviations). In this 472 study, since calculated indexes were generally quite small (below 0.5 ), we multiplied 473 the results of RMSE and $S D$ by 100 to magnify the difference for more intuitive 474
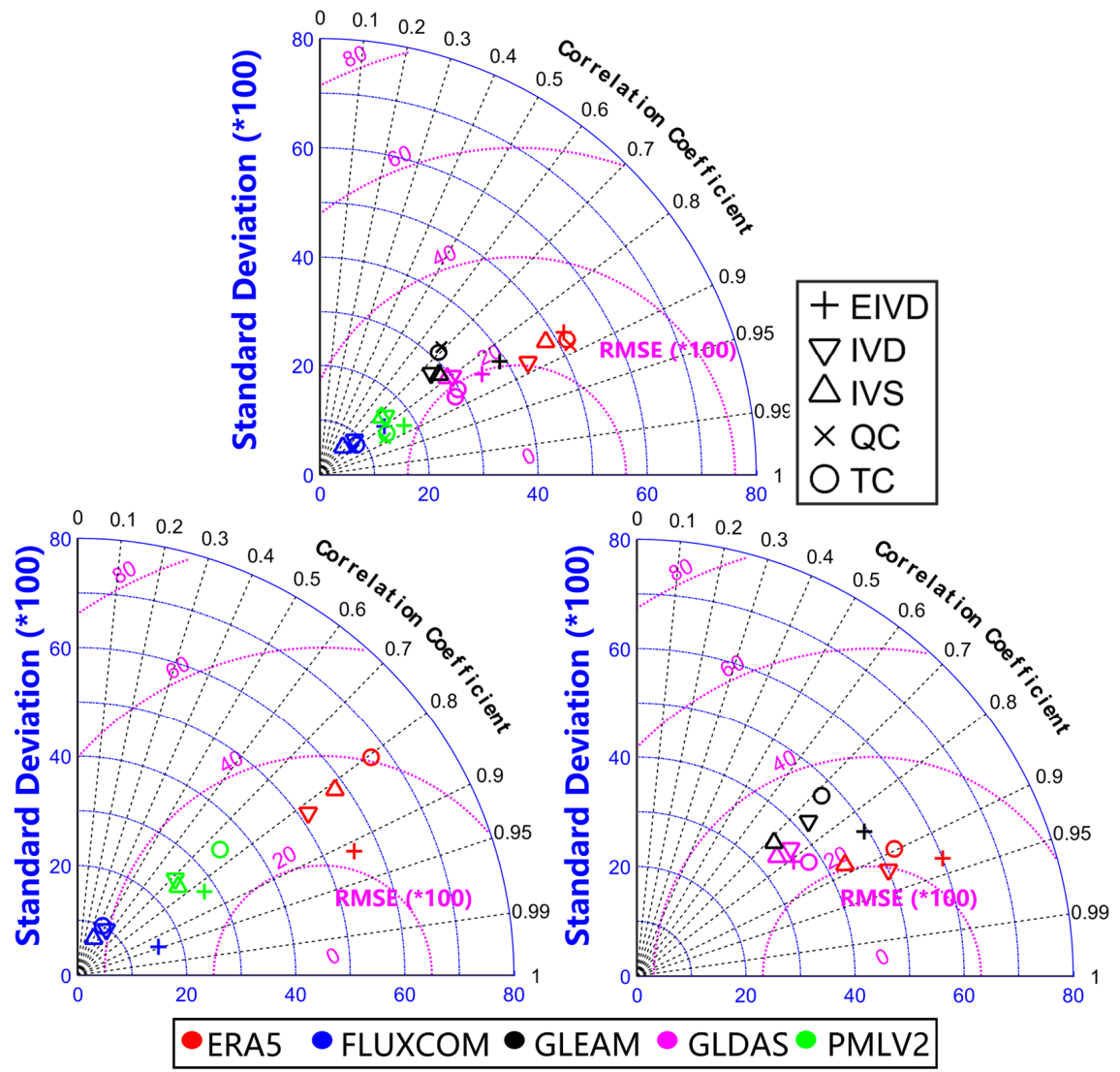
contrast.

FIGURE.4 Taylor diagram for average collocation-based results against evaluations over tower observations of five products. Each color refers to one product and each shape represents one algorithm, as marked in the figure. The diagrams (from left to right) correspond to $0.1^{\circ}-8$ Daily results, $0.25^{\circ}$-Daily results, and $0.25^{\circ}$-8Daily results, 
482 As shown in the figure, the average $R M S E$ was between $0.02-0.04 \mathrm{~mm} / \mathrm{d}$ with mean $483 R^{2}$ over 0.8 , manifesting the overall high accuracy of all products. Moreover, EIVD 484 and IVD methods outperformed others with relatively higher correlation and lower 485 difference, while TC showed the highest RMSE. However, since all the indexes were 486 quite small, it could be concluded that results by any method matched the reference 487 well.

488 In addition, to select the proper error structure and assess the performance of 489 algorithms over various resolution, we compared the ERA5-results based on two error 490 models over two scales. Each column referred to one resolution.

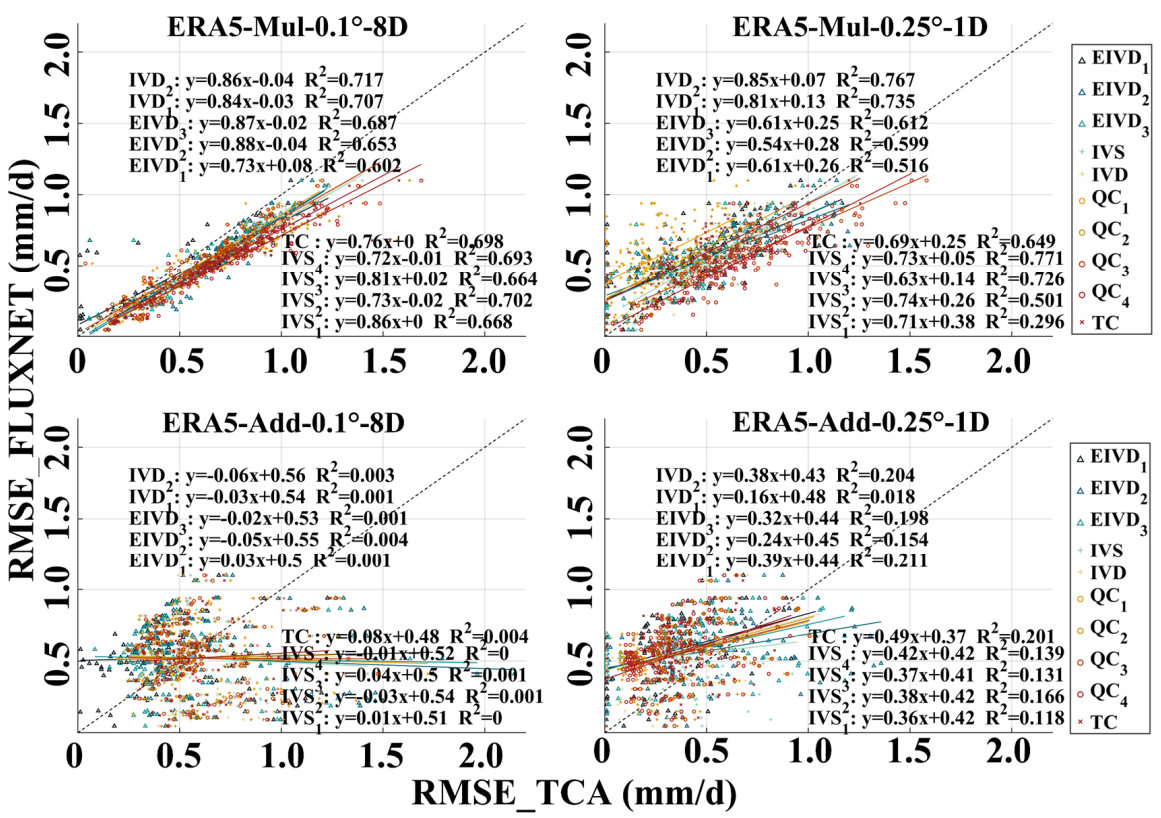

FIGURE.5 Comparison of collocation analysis results for ERA5 using multiplicative

(first row) or additive (second row) error structure at various resolutions against

495 As shown in the figure, there was a poignant contrast of performance between two error models. Multiplicative structure was proven to be a better description of the error-truth-relation, which was consistent with previous research (Yilmaz and Crow, 498 2014; Li et al., 2018). In the contrast, evaluations using additive model showed 
499 dramatical deviation against observation-based results. Thus, we only employed the

500 multiplicative error model for further calculation and analysis.

501 In general, the comparison results demonstrated that collocation methods were

502 reliable for the evaluation of evapotranspiration products. Multiplicative error model

503 was more suitable for the description of error-truth-relation. Among the methods, IVD,

504 EIVD, and QC were the three preferred methods for usage.

\section{5. Results}

506 In this section, we conducted the comparison between merged product and others in

507 two steps: (1) validation at point scale using 82 selected FLUXNET sites; (2)

508 comparison of global spatial distribution and variation trend.

\subsection{Site-based Validation}

510 The validation results of CAMELE against flux tower observations for different land

511 cover types were shown in Figure 6 - 7. The average accuracy of CAMELE was about

$5120.68,0.62$ of correlation and $0.84,1.03 \mathrm{~mm} / \mathrm{d}$ of RMSE over $0.1^{\circ}$ and $0.25^{\circ}$, while

513 ERA5 and GLEAM were the second best for $0.1^{\circ}$ and $0.25^{\circ}$ with 0.66 and 0.61 of

514 correlation. In general, the merged product revealed well performance over all land

515 cover types with some variations. The results also indicated that the uncertainties of

516 products increased over coarser resolution with obvious higher relative bias and lower

517 correlation. Moreover, slight overestimation of merged product was found over $0.25^{\circ}$

518 for generally all land cover types. Since tower or gauge could only cover the variation

519 of geographical variables over a certain range (Tang et al., 2018), pixel-based

520 evaluation on $0.1^{\circ}$ and $0.25^{\circ}$ should consider the inherent uncertainty of in-situ

521 observations, which may explain the increased bias found in our comparison. In

522 general, the validation against flux tower data demonstrated the overall high accuracy

523 of CAMELE over various land cover types. 
https://doi.org/10.5194/essd-2021-456

Preprint. Discussion started: 1 March 2022

(C) Author(s) 2022. CC BY 4.0 License.

527 evergreen needleleaf forests (ENF), evergreen broadleaf forests (EBF), deciduous

528 broadleaf forests (DBF), croplands (CRO), grasslands (GRA), savannas (SAV),

529 woody savannas (WSA), and mixed forests (MF) over $0.1^{\circ}-8$ Daily resolution 


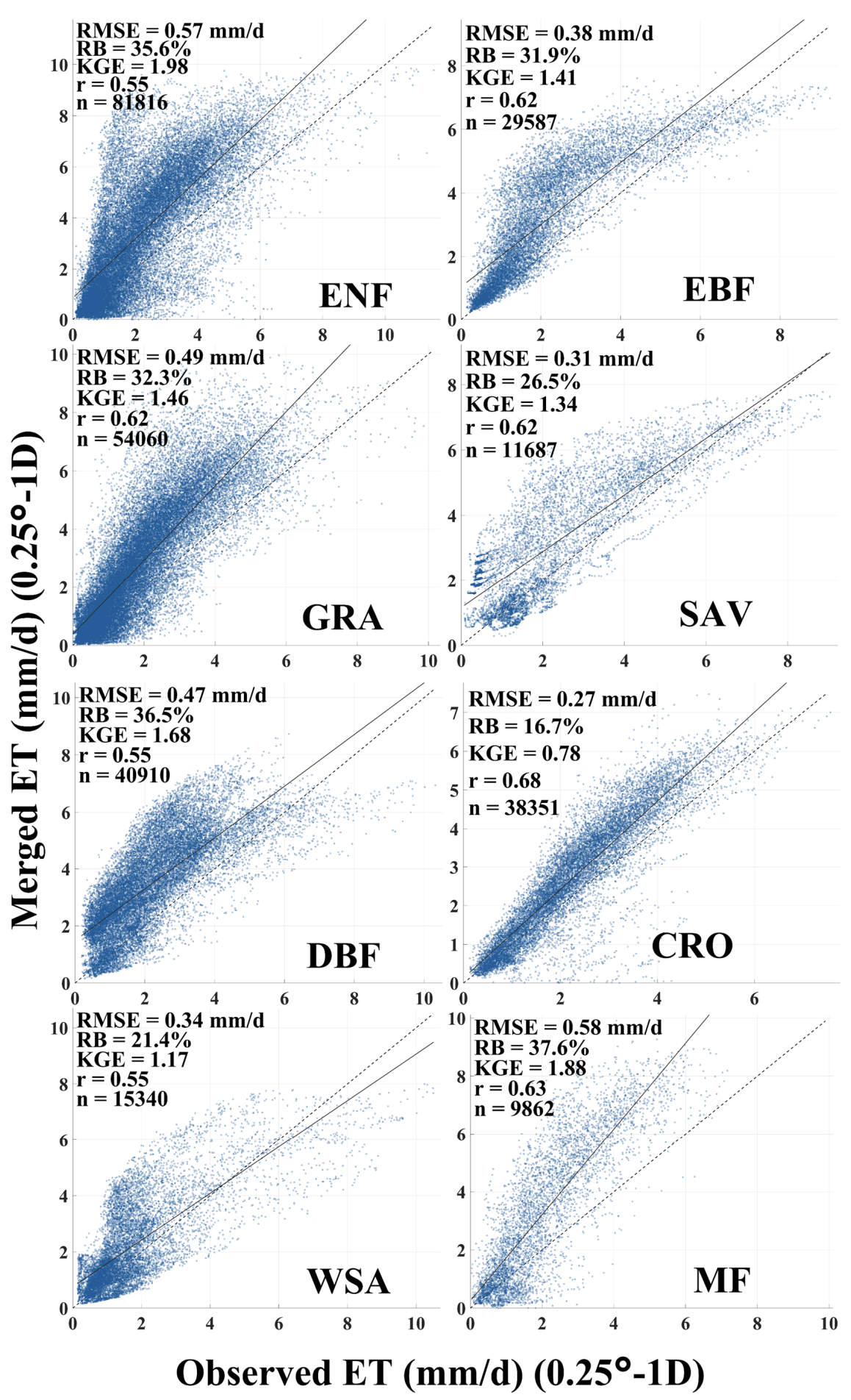


531 FIGURE.7 Validation results of CAMELE against flux tower observations for

532 evergreen needleleaf forests (ENF), evergreen broadleaf forests (EBF), deciduous

533 broadleaf forests (DBF), croplands (CRO), grasslands (GRA), savannas (SAV),

534 woody savannas (WSA), and mixed forests (MF) over $0.25^{\circ}$-Daily resolution

535 Here we also presented the comparison of all products over some sites and employ the

536 Kling-Gupta Efficiency (KGE) for better description. The KGE (Gupta et al., 2009)

537 addressed several shortcomings in Nash-Sutcliffe Efficiency (NSE) and were

538 increasingly used for calibration and evaluation (Knoben et al., 2019), given by:

$$
K G E=1-\sqrt{(r-1)^{2}+\left(\frac{\sigma_{s i m}}{\sigma_{o b s}}-1\right)^{2}+\left(\frac{\mu_{\text {sim }}}{\mu_{o b s}}-1\right)^{2}}
$$

540 Where $\sigma_{o b s}$ and $\sigma_{\text {sim }}$ are the standard deviations of observations and simulations;

$541 \mu_{o b s}$ and $\mu_{\text {sim }}$ are the mean of observations and simulations. Similar with NSE, KGE

$542=1$ indicates perfect agreement of simulations while $\mathrm{KGE}<0$ reveals that the average

543 of observations is better than simulations (Towner et al., 2019; Knoben et al., 2019). 
KGE-BoxChart $\left(0.1^{\circ}-8 D\right)$
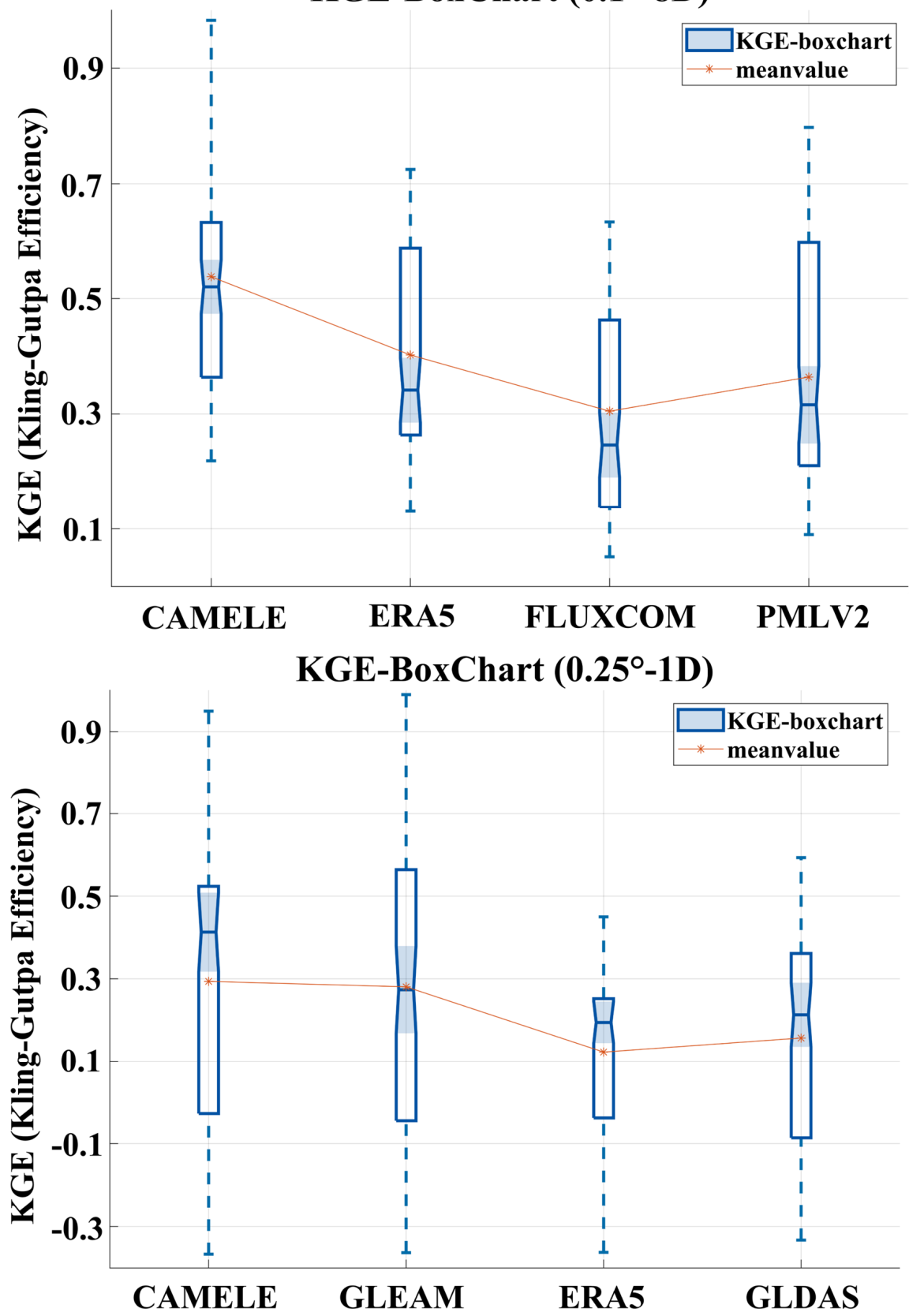

545 FIGURE.8 Boxplots of KGE for all products over two resolutions against 82 sites.

546 In terms of KGE, CAMELE obtained results superior (mean KGE=0.52) to the 
547 second best ERA5 (mean $\mathrm{KGE}=0.44$ ) at $0.1^{\circ}$ basis. In general, our merged product

548 performed well with precise reflection of the fluctuation. At FR-Gri site, some

549 underestimation of PMLV2 and overestimation of FLUXCOM over peak value were

550 observed over $0.1^{\circ}$. At US-Wkg site over $0.25^{\circ}$, all products showed high

551 performance except for ERA5 with significant overestimation. To some extent, our

552 merged product integrated the advantages of all inputs and addressed the

553 overestimation and underestimation of peak value.

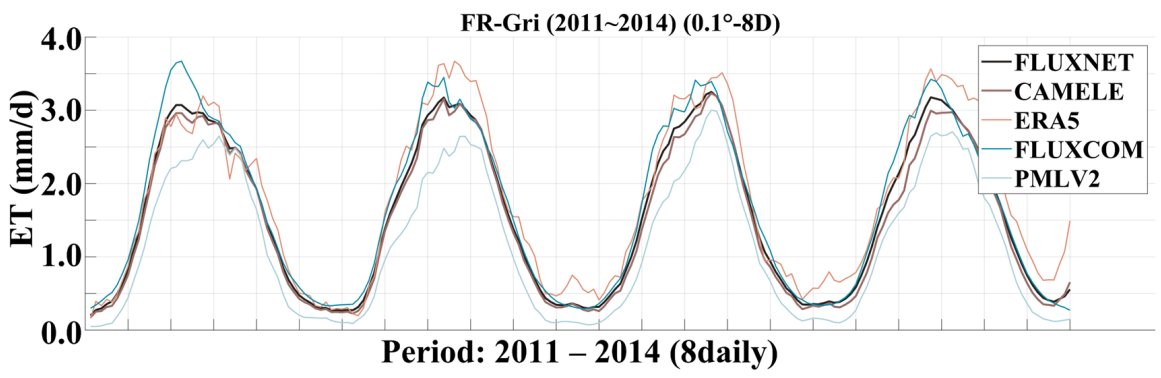

FIGURE.9 Performance of different products at $0.1^{\circ}-8$ Daily resolution on FR-Gri

site from 2011 to 2014 .

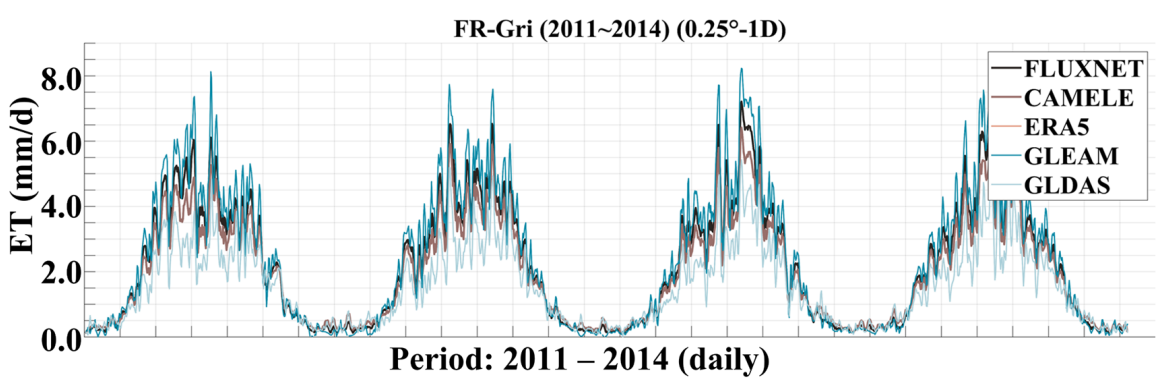

Period: 2011 - 2014 (daily)

FIGURE.10 Performance of different products at $0.25^{\circ}$-Daily resolution on FR-Gri 


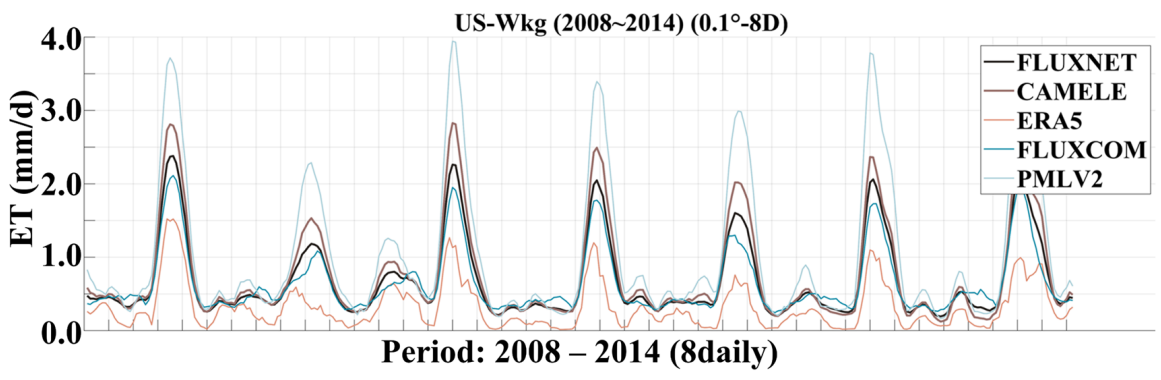

FIGURE.11 Performance of different products at $0.1^{\circ}$-8Daily resolution on US-Wkg site from 2008 to 2014.

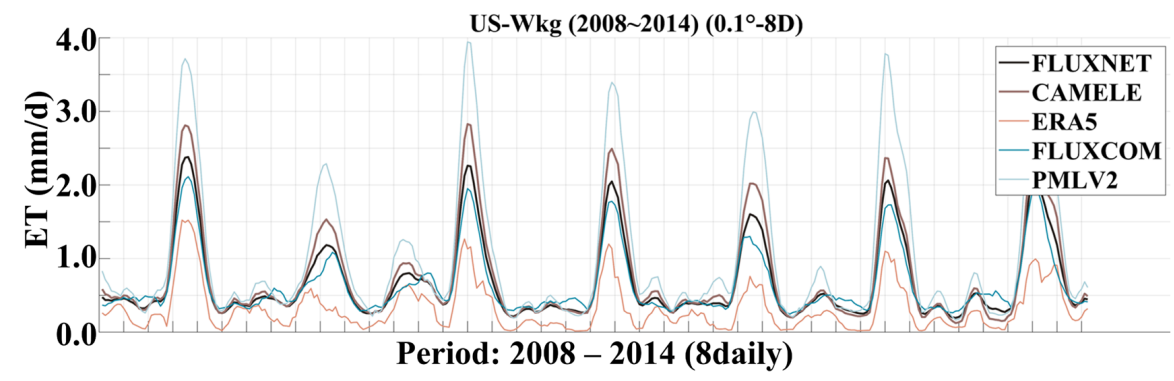

FIGURE.12 Performance of different products at $0.25^{\circ}-1$ Daily resolution on US-

Wkg site from 2008 to 2014.

\subsection{Spatial distribution}

Figure 13 - 14 depicted the spatial distribution of multi-year daily average ET, and the results were found consistent among different products over two resolutions. High evaporation regions were near the equators, including the Amazon Plain in South America, the Congo Basin in central Africa and the border between Asia and Oceania, with high precipitation (usually over $1000 \mathrm{~mm}$ per year). As for extreme low value, they were distributed in permafrost regions or dry desert, like the Sahara and Arabian deserts in North Africa, permafrost regions in North America and Eurasia. Compared to CAMELE, estimations by ERA5 and FLUXCOM were higher in wet regions near the equator while value of PMLV2 was slightly lower over $0.1^{\circ}$; estimations by GLEAM was significant higher near the equators and the value by GLDAS was the 
5882015 and 2003-2017. Over $0.1^{\circ}$, a decrease in ET was found in Amazon Plain and

589 Congo Basin by our merged product, while the increase regions were indicated in

590 South Asia and the West Australia. The reduction over Amazon Plain was also found

591 in ERA5 and FLUXCOM, while PMLV2 showed a rising trend. The decreasing trend

592 over Congo Basin was consistent with ERA5 and FLUXCOM, still an opposite one

593 by PMLV2. (Burnett et al., 2020) demonstrated that Congo Basin had become drier

594 and less humid in recent years based on the analysis of environmental data. Our

595 results showed the same trend.
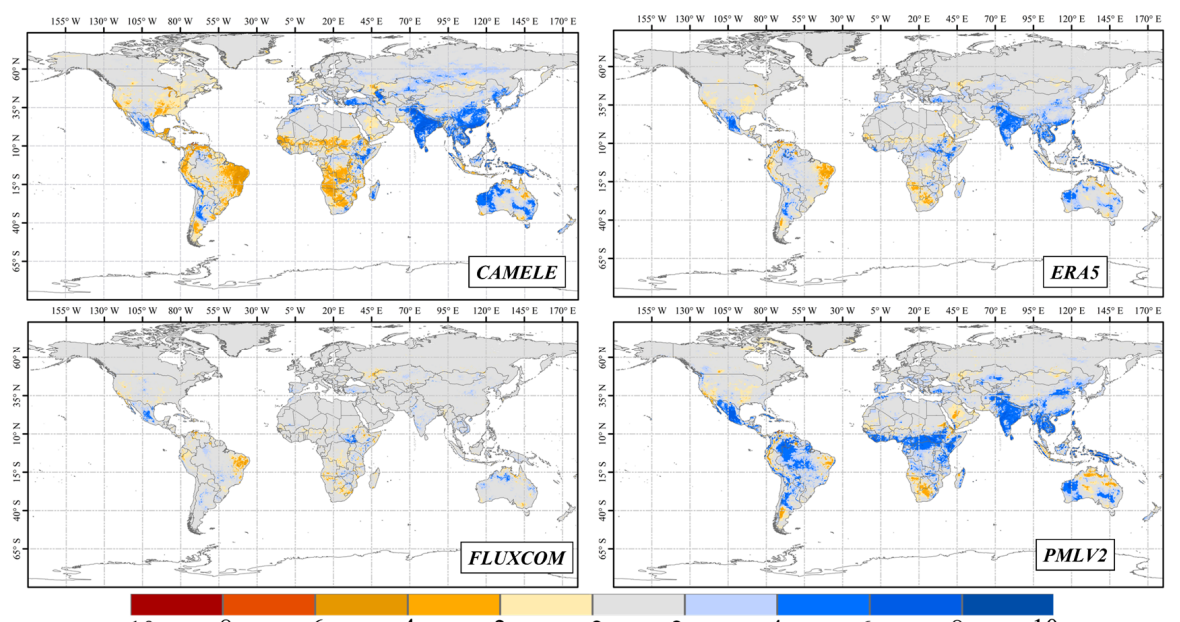

FIGURE.15 Spatial distribution of linear annual trends of land evapotranspiration of 

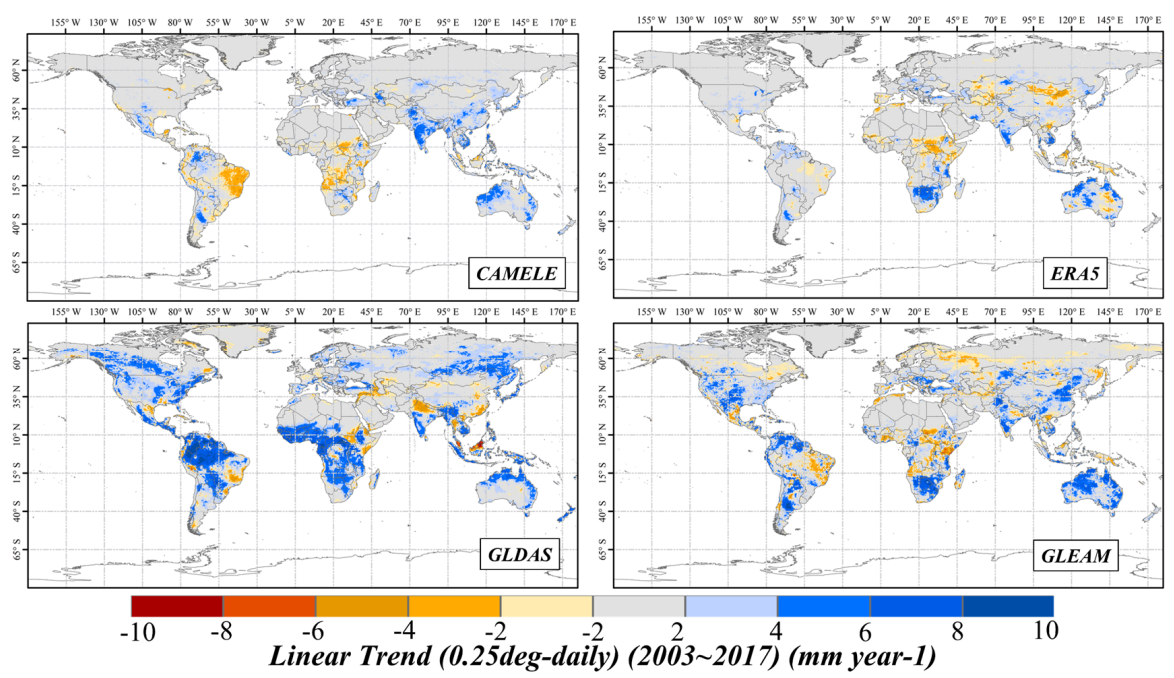

600

601

602

603

604

605

606

607

608

609

610

611

612

613

614

615

616

617

FIGURE.16 Spatial distribution of linear annual trends of land evapotranspiration of different products from 2003 to 2017 over $0.25^{\circ}$-8Daily resolution

Over $0.25^{\circ}$, the variation by merged product followed the similar patterns with the one over $0.1^{\circ}$ with smaller value. This may be explained by the changing of resolution (from $0.1^{\circ}$ to $0.25^{\circ}$ ), which included more pixels into one grid that neutralize the total variation. The general distribution was quite consistent with that of GLEAM, which had been proven with high accuracy, especially over tropical Africa (Liu et al., 2016; Wang et al., 2020). Decreases on Amazon Plain and Congo Basin were also revealed with opposite finding by GLDAS. (Burnett et al., 2020) found GLDAS with the maximum temporal variability among the selected products in their study, especially over Congo Basin. The increases in South Asia and the coastline of Australia were detected in all products.

\section{Conclusion}

In this study, we proposed a collocation-based data merging method and generated a long-period (1980-2020) CAMELE ET product over $0.1^{\circ}$-8Daily and $0.25^{\circ}$-Daily resolutions by merging five widely used datasets, including ERA5, FLUXCOM, PMLV2, GLDAS and GLEAM. The optimal weights were calculated using 
618 evaluations of inputs by collocation methods. The error characterizations were then 619 proven be reliable against evaluations by in-situ observations. In addition, a series of 620 synthetic experiments were design to validate our merging framework. Further, we 621 conducted a comparison between CAMELE and other products at site-based and 622 regional scales. To sum up, our conclusions were as follow:

623 1. Collocation analysis methods could serve as a reliable tool for evaluation of ET 624 products without given reference, which provides promising future for error 625 characterization especially over data-scare region or analysis at global scale. The evaluation results could provide important information for data merging.

627 2. The CAMELE product revealed general good performance at point scale. 628 Compared to in-situ observations, the Pearson Correlation of 0.68 and 0.62 value 629 of CAMELE over $0.1^{\circ}$ and $0.25^{\circ}$ resolutions are higher than the second best for 630 relative resolution ( 0.66 for ERA5 and 0.61 for GLEAM). In addition to Kling631 Gupta Efficiency, the merged product obtained superior mean value of 0.52 , compared to 0.44 for ERA5 at $0.1^{\circ}$ basis.

3. The spatial distributions of multi-year average daily ET and annual variation trend were generally similar to others. Results by CAMELE indicated a decrease in ET over Amazon Plain and Congo Basin, as consistent with the finding by ERA5 and GLEAM. Increases were found in South Asia and Northwest Australia. Our merged product well described the variation of global ET with combining advantages of the input products. The optimal weight for each product was calculated using collocation-based evaluation results. Thus, the uncertainty may come from biased evaluation due to the violation of mathematical assumptions employed by collocation methods, especially 642 the zero ECC assumption. While in our study, the ECC results by EIVD and QC 643 demonstrated that this impact was within acceptable range since the general value of 644 ECC was quite low as presented in the Appendix. Moreover, though random error 645 caused by changing combinations may bring additional uncertainty, previous studies 
646 have showed that the variance over difference combination was quite small ( $\mathrm{Li}$ et al.,

647 2018). Thus, this may not bring much error and could be considered in further study.

648 To sum up, our proposed collocation-based data merging method revealed promising

649 potential for the merging of ET products. The merged CAMELE ET showed general

650 well performance over site-based and regional scales, which could satisfy the

651 requirement of more detailed research. In future studies, to improve the quality of

652 merged product, dynamic weights could be calculated by adopting suitable merging

653 period for different products and more complicated combination schemes could be 654 considered to improve the accuracy.

\section{Author Contribution}

656 LC and $\mathrm{YH}$ designed the research. LC designed the merging method and performed 657 most of calculation and analysis work. LC completed the manuscript and $\mathrm{YW}, \mathrm{LZ}$, 658 YX, YH, LS and YD contributed to the revising and polishing of this paper.

\section{Competing interests}

660 The authors declare that they have no conflict of interest.

661 Acknowledgements

662 We sincerely thank a lot of researchers for their generous help as list below, in no 663 particular order, including: (1) Prof. Stephen Sitch for providing trendy-v8 data and 664 giving suggestion on its usage; (2) Dr. Jianzhi Dong for answering our questions on 665 the employment of EIVD and IVD methods; (3) Dr. Dongdong Kong for providing 666 the latest version of PMLV2; (4) Dr. Peter Weston for further instruction on the usage 667 of MSE merging method; (5) Dr. Liming He for providing the BEPS-ET data and 668 further suggestion on the evaluation of different products; (6) Dr.Youngryel Ryu for 669 providing BESS-ET data. (7) Dr. Martin Jung and Dr. Ulrich Weber for addressing 
670 the data portal for the usage of FLUXCOM. Though some products provided were not

671 used in this study, it was still very helpful for our selection of inputs.

\section{Financial support}

673 This research has been supported by the China National Key R\&D Program (grant no.

6742021 YFC3000202) and the National Natural Science Foundation of China (grant no.

$67551979140,42041004)$

\section{Data availability}

All data used in this study could be accessed via the links described in Data Section. CAMELE products is freely available at https://doi.org/10.5281/zenodo.6283239 (Li et al., 2021) over $0.1^{\circ}$-8Daily and $0.25^{\circ}$-Daily resolutions. The data are distributed under a Creative Commons Attribution 4.0 License.

\section{Reference}

Baik, J., Park, J., Hao, Y., and Choi, M.: Integration of multiple drought indices using a triple collocation approach, Stochastic Environmental Research and Risk Assessment, 1-19, 2021.

Baker, J. C. A., Garcia-Carreras, L., Gloor, M., Marsham, J. H., Buermann, W., da Rocha, H. R., Nobre, A. D., de Araujo, A. C., and Spracklen, D. V.: Evapotranspiration in the Amazon: spatial patterns, seasonality, and recent trends in observations, reanalysis, and climate models, Hydrology and Earth System Sciences, 25, 2279-2300, 10.5194/hess-25-2279-2021, 2021.

Bates, J. M. and Granger, C. W.: The combination of forecasts, Journal of the Operational Research Society, 20, 451-468, 1969.

Biscarini, M., Vittimberga, A., De Sanctis, K., Fabio, S. D., Montagna, M., Milani, L., Tsuda, Y., and Marzano, F. S.: Optimal Stochastic Prediction and Verification of Signal-to-Noise Ratio and Data Rate for Ka-Band Spaceborne Telemetry Using Weather Forecasts, IEEE Transactions on Antennas and Propagation, 69, 10651077, 10.1109/tap.2020.3016865, 2021.

Burnett, M. W., Quetin, G. R., and Konings, A. G.: Data-driven estimates of evapotranspiration and its controls in the Congo Basin, Hydrology and Earth System Sciences, 24, 4189-4211, 10.5194/hess-24-4189-2020, 2020. 
Chen, F., Crow, W. T., Bindlish, R., Colliander, A., Burgin, M. S., Asanuma, J., and Aida, K.: Global-scale evaluation of SMAP, SMOS and ASCAT soil moisture products using triple collocation, Remote Sensing of Environment, 214, 1-13, 10.1016/j.rse.2018.05.008, 2018.

Chen, Z., Zhu, Z., Jiang, H., and Sun, S.: Estimating daily reference evapotranspiration based on limited meteorological data using deep learning and classical machine learning methods, Journal of Hydrology, 591, 10.1016/j.jhydrol.2020.125286, 2020.

Decker, M., Brunke, M. A., Wang, Z., Sakaguchi, K., Zeng, X., and Bosilovich, M. G.: Evaluation of the Reanalysis Products from GSFC, NCEP, and ECMWF Using Flux Tower Observations, Journal of Climate, 25, 1916-1944, 10.1175/jcli-d-11-00004.1, 2012.

Dong, J., Lei, F., and Wei, L.: Triple collocation based multi-source precipitation merging, Frontiers in Water, 2, 1, 2020a.

Dong, J., Crow, W. T., Duan, Z., Wei, L., and Lu, Y.: A double instrumental variable method for geophysical product error estimation, Remote Sensing of Environment, 225, 217-228, 10.1016/j.rse.2019.03.003, 2019.

Dong, J., Wei, L., Chen, X., Duan, Z., and Lu, Y.: An instrument variable based algorithm for estimating cross-correlated hydrological remote sensing errors, Journal of Hydrology, 581, 124413, 10.1016/j.jhydrol.2019.124413, 2020 b.

Dong, J., Dirmeyer, P. A., Lei, F., Anderson, M. C., Holmes, T. R. H., Hain, C., and Crow, W. T.: Soil Evaporation Stress Determines Soil MoistureEvapotranspiration Coupling Strength in Land Surface Modeling, Geophysical Research Letters, 47, 10.1029/2020g1090391, 2020c.

Ershadi, A., McCabe, M. F., Evans, J. P., Chaney, N. W., and Wood, E. F.: Multi-site evaluation of terrestrial evaporation models using FLUXNET data, Agricultural and Forest Meteorology, 187, 46-61, 10.1016/j.agrformet.2013.11.008, 2014.

Feng, Y., Cui, N., Zhao, L., Hu, X., and Gong, D.: Comparison of ELM, GANN, WNN and empirical models for estimating reference evapotranspiration in humid region of Southwest China, Journal of Hydrology, 536, 376-383, 10.1016/j.jhydrol.2016.02.053, 2016.

Gan, R., Zhang, Y., Shi, H., Yang, Y., Eamus, D., Cheng, L., Chiew, F. H., and Yu, Q.: Use of satellite leaf area index estimating evapotranspiration and gross assimilation for Australian ecosystems, Ecohydrology, 11, e1974, 2018.

Gentine, P., Massmann, A., Lintner, B. R., Hamed Alemohammad, S., Fu, R., Green, J. K., Kennedy, D., and Vilà-Guerau de Arellano, J.: Land-atmosphere interactions in the tropics - a review, Hydrology and Earth System Sciences, 23, 4171-4197, 10.5194/hess-23-4171-2019, 2019.

Griebel, A., Metzen, D., Pendall, E., Burba, G., and Metzger, S.: Generating spatially robust carbon budgets from flux tower observations, Geophysical Research Letters, 47, e2019GL085942, 2020.

Gruber, A., Su, C. H., Zwieback, S., Crow, W., Dorigo, W., and Wagner, W.: Recent 
advances in (soil moisture) triple collocation analysis, International Journal of Applied Earth Observation and Geoinformation, 45, 200-211, 10.1016/j.jag.2015.09.002, 2016.

Gruber, A., De Lannoy, G., Albergel, C., Al-Yaari, A., Brocca, L., Calvet, J. C., Colliander, A., Cosh, M., Crow, W., Dorigo, W., Draper, C., Hirschi, M., Kerr, Y., Konings, A., Lahoz, W., McColl, K., Montzka, C., Muñoz-Sabater, J., Peng, J., Reichle, R., Richaume, P., Rüdiger, C., Scanlon, T., Van Der Schalie, R., Wigneron, J. P., and Wagner, W.: Validation practices for satellite soil moisture retrievals: What are (the) errors?, Remote Sensing of Environment, 244, 111806, 10.1016/j.rse.2020.111806, 2020.

Gupta, H. V., Kling, H., Yilmaz, K. K., and Martinez, G. F.: Decomposition of the mean squared error and NSE performance criteria: Implications for improving hydrological modelling, Journal of hydrology, 377, 80-91, 2009.

Han, S. and Tian, F.: A review of the complementary principle of evaporation: from the original linear relationship to generalized nonlinear functions, Hydrology and Earth System Sciences, 24, 2269-2285, 10.5194/hess-24-2269-2020, 2020.

Hersbach, H., Bell, B., Berrisford, P., Hirahara, S., Horányi, A., Muñoz-Sabater, J., Nicolas, J., Peubey, C., Radu, R., Schepers, D., Simmons, A., Soci, C., Abdalla, S., Abellan, X., Balsamo, G., Bechtold, P., Biavati, G., Bidlot, J., Bonavita, M., Chiara, G., Dahlgren, P., Dee, D., Diamantakis, M., Dragani, R., Flemming, J., Forbes, R., Fuentes, M., Geer, A., Haimberger, L., Healy, S., Hogan, R. J., Hólm, E., Janisková, M., Keeley, S., Laloyaux, P., Lopez, P., Lupu, C., Radnoti, G., Rosnay, P., Rozum, I., Vamborg, F., Villaume, S., and Thépaut, J. N.: The ERA5 global reanalysis, Quarterly Journal of the Royal Meteorological Society, 146, 1999-2049, 10.1002/qj.3803, 2020.

Hoareau, N., Portabella, M., Lin, W., Ballabrera-Poy, J., and Turiel, A.: Error characterization of sea surface salinity products using triple collocation analysis, IEEE Transactions on Geoscience and Remote Sensing, 56, 5160-5168, 2018.

Jiang, C., Ryu, Y., Fang, H., Myneni, R., Claverie, M., and Zhu, Z.: Inconsistencies of interannual variability and trends in long-term satellite leaf area index products, Global Change Biology, 23, 4133-4146, 2017.

Jung, M., Koirala, S., Weber, U., Ichii, K., Gans, F., Camps-Valls, G., Papale, D., Schwalm, C., Tramontana, G., and Reichstein, M.: The FLUXCOM ensemble of global land-atmosphere energy fluxes, Scientific Data, 6, 10.1038/s41597-0190076-8, 2019.

Jung, M., Reichstein, M., Ciais, P., Seneviratne, S. I., Sheffield, J., Goulden, M. L., Bonan, G., Cescatti, A., Chen, J., and De Jeu, R.: Recent decline in the global land evapotranspiration trend due to limited moisture supply, Nature, 467, 951954, 2010.

Kim, S., Pham, H. T., Liu, Y. Y., Marshall, L., and Sharma, A.: Improving the Combination of Satellite Soil Moisture Data Sets by Considering Error Cross Correlation: A Comparison Between Triple Collocation (TC) and Extended 
Double Instrumental Variable (EIVD) Alternatives, IEEE Transactions on Geoscience and Remote Sensing, 1-11, 10.1109/tgrs.2020.3032418, 2020.

Knauer, J., Zaehle, S., Medlyn, B. E., Reichstein, M., Williams, C. A., Migliavacca, M., De Kauwe, M. G., Werner, C., Keitel, C., Kolari, P., Limousin, J. M., and Linderson, M. L.: Towards physiologically meaningful water-use efficiency estimates from eddy covariance data, Glob Chang Biol, 24, 694-710, 10.1111/gcb.13893, 2018.

Knoben, W. J. M., Freer, J. E., and Woods, R. A.: Technical note: Inherent benchmark or not? Comparing Nash-Sutcliffe and Kling-Gupta efficiency scores, Hydrology and Earth System Sciences, 23, 4323-4331, 10.5194/hess-23-43232019, 2019.

Kong, D., Gu, X., Li, J., Ren, G., and Liu, J.: Contributions of Global Warming and Urbanization to the Intensification of Human-Perceived Heatwaves Over China, Journal of Geophysical Research: Atmospheres, 125, 10.1029/2019jd032175, 2020.

Koster, R. D., Liu, Q., Reichle, R. H., and Huffman, G. J.: Improved Estimates of Pentad Precipitation Through the Merging of Independent Precipitation Data Sets, Water Resources Research, 57, 10.1029/2021wr030330, 2021.

Le, H., Yang, N., Liu, L., Chen, Y., and Zhang, H.: The latitudinal structure of nighttime ionospheric TEC and its empirical orthogonal functions model over North American sector, Journal of Geophysical Research: Space Physics, 122, 963-977, 10.1002/2016ja023361, 2017.

Leuning, R., Zhang, Y., Rajaud, A., Cleugh, H., and Tu, K.: A simple surface conductance model to estimate regional evaporation using MODIS leaf area index and the Penman-Monteith equation, Water Resources Research, 44, 2008.

Li, C., Tang, G., and Hong, Y.: Cross-evaluation of ground-based, multi-satellite and reanalysis precipitation products: Applicability of the Triple Collocation method across Mainland China, Journal of Hydrology, 562, 71-83, 10.1016/j.jhydrol.2018.04.039, 2018.

Li Changming, Yang Hanbo, Yang Wencong, Liu Ziwei, Jia Yao, Li Sienand Yang Dawen: CAMELE: Collocation-Analyzed Multi-source Ensembled Land Evapotranspiration Data, https://doi.org/10.5281/zenodo.6283239, 2021.

Li, K., Tian, F., Khan, M. Y. A., Xu, R., He, Z., Yang, L., Lu, H., and Ma, Y.: A highaccuracy rainfall dataset by merging multiple satellites and dense gauges over the southern Tibetan Plateau for 2014-2019 warm seasons, Earth System Science Data, 13, 5455-5467, 10.5194/essd-13-5455-2021, 2021.

Li, X., Gentine, P., Lin, C., Zhou, S., Sun, Z., Zheng, Y., Liu, J., and Zheng, C.: A simple and objective method to partition evapotranspiration into transpiration and evaporation at eddy-covariance sites, Agricultural and Forest Meteorology, 265, 171-182, 10.1016/j.agrformet.2018.11.017, 2019.

Lian, X., Piao, S., Huntingford, C., Li, Y., Zeng, Z., Wang, X., Ciais, P., McVicar, T. R., Peng, S., and Ottlé, C.: Partitioning global land evapotranspiration using 
CMIP5 models constrained by observations, Nature Climate Change, 8, 640-646, 2018.

Lin, C., Gentine, P., Frankenberg, C., Zhou, S., Kennedy, D., and Li, X.: Evaluation and mechanism exploration of the diurnal hysteresis of ecosystem fluxes, Agricultural and Forest Meteorology, 278, 10.1016/j.agrformet.2019.107642, 2019.

Liu, W., Wang, L., Zhou, J., Li, Y., Sun, F., Fu, G., Li, X., and Sang, Y.-F.: A worldwide evaluation of basin-scale evapotranspiration estimates against the water balance method, Journal of Hydrology, 538, 82-95, 10.1016/j.jhydrol.2016.04.006, 2016.

Loveland, T. R., Zhu, Z., Ohlen, D. O., Brown, J. F., Reed, B. C., and Yang, L.: An analysis of the IGBP global land-cover characterization process, Photogrammetric engineering and remote sensing, 65, 1021-1032, 1999.

Ma, Y., Hu, Z., Xie, Z., Ma, W., Wang, B., Chen, X., Li, M., Zhong, L., Sun, F., Gu, L., Han, C., Zhang, L., Liu, X., Ding, Z., Sun, G., Wang, S., Wang, Y., and Wang, Z.: A long-term (2005-2016) dataset of hourly integrated land-atmosphere interaction observations on the Tibetan Plateau, Earth System Science Data, 12, 2937-2957, 10.5194/essd-12-2937-2020, 2020.

Majozi, N. P., Mannaerts, C. M., Ramoelo, A., Mathieu, R., Nickless, A., and Verhoef, W.: Analysing surface energy balance closure and partitioning over a semi-arid savanna FLUXNET site in Skukuza, Kruger National Park, South Africa, Hydrology and Earth System Sciences, 21, 3401-3415, 10.5194/hess-21-34012017, 2017.

Martens, B., Miralles, D. G., Lievens, H., van der Schalie, R., de Jeu, R. A. M., Fernández-Prieto, D., Beck, H. E., Dorigo, W. A., and Verhoest, N. E. C.: GLEAM v3: satellite-based land evaporation and root-zone soil moisture, Geoscientific Model Development, 10, 1903-1925, 10.5194/gmd-10-1903-2017, 2017.

McColl, K. A., Roy, A., Derksen, C., Konings, A. G., Alemohammed, S. H., and Entekhabi, D.: Triple collocation for binary and categorical variables: Application to validating landscape freeze/thaw retrievals, 176, 31-42, 10.1016/j.rse.2016.01.010, 2016.

Medlyn, B. E., De Kauwe, M. G., Lin, Y. S., Knauer, J., Duursma, R. A., Williams, C. A., Arneth, A., Clement, R., Isaac, P., Limousin, J. M., Linderson, M. L., Meir, P., Martin-StPaul, N., and Wingate, L.: How do leaf and ecosystem measures of water-use efficiency compare?, New Phytol, 216, 758-770, 10.1111/nph.14626, 2017.

Miralles, D. G., Gentine, P., Seneviratne, S. I., and Teuling, A. J.: Land-atmospheric feedbacks during droughts and heatwaves: state of the science and current challenges, Annals of the New York Academy of Sciences, 1436, 19, 2019.

Miralles, D. G., Holmes, T. R. H., De Jeu, R. A. M., Gash, J. H., Meesters, A. G. C. A., and Dolman, A. J.: Global land-surface evaporation estimated from satellite- 
based observations, Hydrology and Earth System Sciences, 15, 453-469, 10.5194/hess-15-453-2011, 2011.

Pan, S., Pan, N., Tian, H., Friedlingstein, P., Sitch, S., Shi, H., Arora, V. K., Haverd, V., Jain, A. K., Kato, E., Lienert, S., Lombardozzi, D., Nabel, J. E. M. S., Ottlé, C., Poulter, B., Zaehle, S., and Running, S. W.: Evaluation of global terrestrial evapotranspiration using state-of-the-art approaches in remote sensing, machine learning and land surface modeling, Hydrology and Earth System Sciences, 24, 1485-1509, 10.5194/hess-24-1485-2020, 2020.

Pastorello, G., Trotta, C., Canfora, E., Chu, H., Christianson, D., Cheah, Y.-W., Poindexter, C., Chen, J., Elbashandy, A., and Humphrey, M.: The FLUXNET2015 dataset and the ONEFlux processing pipeline for eddy covariance data, Scientific data, 7, 1-27, 2020.

Priestley, C. H. B. and TAYLOR, R. J.: On the assessment of surface heat flux and evaporation using large-scale parameters, Monthly weather review, 100, 81-92, 1972.

Restrepo-Coupe, N., Albert, L. P., Longo, M., Baker, I., Levine, N. M., Mercado, L. M., da Araujo, A. C., Christoffersen, B. O., Costa, M. H., Fitzjarrald, D. R., Galbraith, D., Imbuzeiro, H., Malhi, Y., von Randow, C., Zeng, X., Moorcroft, P., and Saleska, S. R.: Understanding water and energy fluxes in the Amazonia: Lessons from an observation-model intercomparison, Glob Chang Biol, 27, 1802-1819, 10.1111/gcb.15555, 2021.

Ribal, A. and Young, I. R.: Global Calibration and Error Estimation of Altimeter, Scatterometer, and Radiometer Wind Speed Using Triple Collocation, Remote Sensing, 12, 10.3390/rs12121997, 2020.

Rodell, M., Houser, P., Jambor, U., Gottschalck, J., Mitchell, K., Meng, C.-J., Arsenault, K., Cosgrove, B., Radakovich, J., and Bosilovich, M.: The global land data assimilation system, Bulletin of the American Meteorological Society, 85, 381-394, 2004.

Sharma, K., Irmak, S., and Kukal, M. S.: Propagation of soil moisture sensing uncertainty into estimation of total soil water, evapotranspiration and irrigation decision-making, Agricultural Water Management, 243, 106454, 2021.

Stoffelen, A.: Toward the true near-surface wind speed: Error modeling and calibration using triple collocation, Journal of Geophysical Research: Oceans, 103, 7755-7766, 10.1029/97jc03180, 1998.

Su, C.-H., Ryu, D., Crow, W. T., and Western, A. W.: Beyond triple collocation: Applications to soil moisture monitoring, Journal of Geophysical Research: Atmospheres, 119, 6419-6439, 10.1002/2013jd021043, 2014.

Sun, J., McColl, K. A., Wang, Y., Rigden, A. J., Lu, H., Yang, K., Li, Y., and Santanello, J. A.: Global evaluation of terrestrial near-surface air temperature and specific humidity retrievals from the Atmospheric Infrared Sounder (AIRS), Remote Sensing of Environment, 252, 10.1016/j.rse.2020.112146, 2021.

Tang, G., Behrangi, A., Long, D., Li, C., and Hong, Y.: Accounting for spatiotemporal 
errors of gauges: A critical step to evaluate gridded precipitation products, Journal of Hydrology, 559, 294-306, 10.1016/j.jhydrol.2018.02.057, 2018.

Taylor, K. E.: Summarizing multiple aspects of model performance in a single diagram, Journal of Geophysical Research: Atmospheres, 106, 7183-7192, 2001.

Towner, J., Cloke, H. L., Zsoter, E., Flamig, Z., Hoch, J. M., Bazo, J., Coughlan de Perez, E., and Stephens, E. M.: Assessing the performance of global hydrological models for capturing peak river flows in the Amazon basin, Hydrology and Earth System Sciences, 23, 3057-3080, 10.5194/hess-23-3057-2019, 2019.

Twine, T. E., Kustas, W., Norman, J., Cook, D., Houser, P., Meyers, T., Prueger, J., Starks, P., and Wesely, M.: Correcting eddy-covariance flux underestimates over a grassland, Agricultural and forest meteorology, 103, 279-300, 2000.

Vogelzang, J. and Stoffelen, A.: Quadruple Collocation Analysis of In-Situ, Scatterometer, and NWP Winds, Journal of Geophysical Research: Oceans, 126, 10.1029/2021jc017189, 2021.

Wang, F., Liang, W., Fu, B., Jin, Z., Yan, J., Zhang, W., Fu, S., and Yan, N.: Changes of cropland evapotranspiration and its driving factors on the loess plateau of China, Sci Total Environ, 728, 138582, 10.1016/j.scitotenv.2020.138582, 2020.

Yilmaz, M. T. and Crow, W. T.: Evaluation of Assumptions in Soil Moisture Triple Collocation Analysis, Journal of Hydrometeorology, 15, 1293-1302, 10.1175/jhm-d-13-0158.1, 2014.

Yin, L., Tao, F., Chen, Y., Liu, F., and Hu, J.: Improving terrestrial evapotranspiration estimation across China during 2000-2018 with machine learning methods, Journal of Hydrology, 600, 10.1016/j.jhydrol.2021.126538, 2021.

Yoo, B. H., Kim, J., Lee, B. W., Hoogenboom, G., and Kim, K. S.: A surrogate weighted mean ensemble method to reduce the uncertainty at a regional scale for the calculation of potential evapotranspiration, Sci Rep, 10, 870, 10.1038/s41598-020-57466-0, 2020.

Zhang, C., Abbaszadeh, P., Xu, L., Moradkhani, H., Duan, Q., and Gong, W.: A Combined Optimization-Assimilation Framework to Enhance the Predictive Skill of Community Land Model, Water Resources Research, 57, 10.1029/2021wr029879, 2021a.

Zhang, K., Kimball, J. S., Kim, Y., and McDonald, K. C.: Changing freeze-thaw seasons in northern high latitudes and associated influences on evapotranspiration, Hydrological Processes, 25, 4142-4151, 10.1002/hyp.8350, 2011.

Zhang, L., Marshall, M., Nelson, A., and Vrieling, A.: A global assessment of PT-JPL soil evaporation in agroecosystems with optical, thermal, and microwave satellite data, Agricultural and Forest Meteorology, 306, 10.1016/j.agrformet.2021.108455, 2021b.

Zhang, Y., Leuning, R., Hutley, L. B., Beringer, J., McHugh, I., and Walker, J. P.: Using long-term water balances to parameterize surface conductances and calculate evaporation at 0.05 spatial resolution, Water Resources Research, 46, 
$952 \quad 2010$.

953 Zhang, Y., Kong, D., Gan, R., Chiew, F. H. S., McVicar, T. R., Zhang, Q., and Yang, 954 Y.: Coupled estimation of $500 \mathrm{~m}$ and 8-day resolution global evapotranspiration 955 and gross primary production in 2002-2017, Remote Sensing of Environment, $956 \quad 222,165-182,10.1016 /$ j.rse.2018.12.031, 2019.

957 Zhu, G., Li, X., Zhang, K., Ding, Z., Han, T., Ma, J., Huang, C., He, J., and Ma, T.: 958 Multi-model ensemble prediction of terrestrial evapotranspiration across north 959 China using Bayesian model averaging, Hydrological Processes, 30, 2861-2879, $960 \quad$ 10.1002/hyp.10832, 2016.

961 